\title{
Selective pericentromeric heterochromatin dismantling caused by TP53 activation during senescence
}

\section{Aaron Mendez-Bermudez}

Université Côte d'Azur

Mélanie Pousse

Université Côte d'Azur

Liudmyla Lototska

Université Côte d'Azur

Florent Tessier

Université Côte d'Azur

Olivier Croce

Université Côte d'Azur

Chrysa Latrick

Université Côte d'Azur

Veronica Cherdyntseva

Biomedical Research Foundation of the Academy of Athens

Joe Nassour

Institut Pasteur de Lille

Xiaohua JIANG

Chinese University of Hong Kong

\section{Yiming LU}

Shanghai Ruijin Hospital, Shanghai Jiaotong University school of Medicine

Corinne Abbadie

UMR Univ Lille-CNRS9020-Inserm1277-CHU Lille-Institut Pasteur de Lille https://orcid.org/0000-0002-

8174-2393

\section{Sarantis Gagos}

Biomedical Research Foundation of the Academy of Athens

Jing Ye

Ruijin Hospital

Eric Gilson ( $\nabla$ eric.gilson@unice.fr)

Université Côte d'Azur https://orcid.org/0000-0001-5738-6723 
Keywords: cellular senescence, aging, telomere shortening, consititutive heterochromatin loss,

Posted Date: June 16th, 2021

DOI: https://doi.org/10.21203/rs.3.rs-583132/v1

License: (c) (1) This work is licensed under a Creative Commons Attribution 4.0 International License. Read Full License 


\section{Selective pericentromeric heterochromatin dismantling caused by TP53 activation during senescence}

Aaron Mendez-Bermudez ${ }^{1,2}$, Melanie Pousse ${ }^{2}$, Liudmyla Lototska², Florent Tessier ${ }^{2}$,

Oliver Croce ${ }^{2}$, Chrysa M Latrick², Veronica Cherdyntseva ${ }^{3}$, Joe Nassour ${ }^{4}$, Jiang Xiaohua ${ }^{5}$, Yiming Lu ${ }^{1}$, Corinne Abbadie ${ }^{4}$, Sarantis Gagos ${ }^{3}$, Jing Ye ${ }^{1 \#}$, Eric Gilson ${ }^{1,2,6 \#^{*}}$

1 International laboratory in Hematology, Cancer and Aging, Pôle Sino-Français de Recherches en Sciences du Vivant et Génomique, Rui Jin Hospital, Shanghai Jiao Tong University School of Medicine, Shanghai, China/CNRS/INSERM/University Côte d'Azur.

2 Université Côte d'Azur, CNRS, INSERM, IRCAN, Faculty of Medicine Nice, France 3 Laboratory of Genetics, Center of Experimental Medicine and Translational Research, Biomedical Research Foundation of the Academy of Athens, Greece 4 Univ. Lille, CNRS, Inserm, CHU Lille, Institut Pasteur de Lille, UMR9020-U1277, CANTHER, Cancer Heterogeneity Plasticity and Resistance to Therapies, F-59000 Lille, France

5 School of Biomedical Sciences, The Chinese University of Hong Kong

6 Department of medical genetics, $\mathrm{CHU}$, Nice, France

\section{* Lead Author}

\# Correspondence:

Pr. Eric Gilson, University Côte d'Azur, CHU, IRCAN, Faculty of Medicine, 28 Avenue de Valombrose, 06107 Nice cedex 2, France. E-mail: eric.gilson@unice.fr, Fax: (33) 49337092.

Pr. Jing Ye, Rui Jin Hospital affiliated to Shanghai Jiao Tong University School of Medicine, Ruijin Second Road No.197 Building 11, Luwan District, Shanghai, China. Tel: +8613585625087. Fax: +86 21 64671676. Email: yj11254@rjh.com.cn.

\section{Summary}

Cellular senescence triggers various types of heterochromatin remodelling that contribute to aging. However the age-ralated mechanisms that lead to these epigenetic alterations remain elusive. Here, we asked how two key aging hallmarks, telomere shortening and consititutive heterochromatin loss, are mechanistically connected during senescence. We show that, at the onset of senescence, pericentromeric heterochromatin is specifically dismantled 
consisting of chromatin decondensation, accumulation of DNA breakages, illegitimate recombination and loss of DNA. This process is caused by telomere shortening or genotoxic stress by a sequence of events starting from p53dependent downregulation of the telomere protective protein TRF2. The resulting loss of TRF2 at pericentromeres trigger DNA breaks activating ATM, which in turn leads to heterochromatin decondensation by releasing Kap1 and Lamin B1, recombination and satellite DNA excision found in the cytosol associated to cGAS. This TP53-TRF2 axis activates the interferon response and the formation of chromosome rearrangements when the cells escape the senescent growth arrest. Overall, these results reveal the role of p53 as pericentromeric disassembler and define the basic principles of how a TP53dependent senescence inducer hierarchically leadns to selective pericentromeric dismantling through the downregulation of TRF2.

Aging is a multifactorial process that results in progressive loss of regenerative capacity and tissue function, while simultaneously promotes the development of a large panel of age-related diseases ${ }^{1}$. Evidence suggests that cellular senescence is a basic aging process that is pivotal to drive these changes ${ }^{2}$. Senescence is a permanent non-dividing cellular state triggered by numerous stressors leading to the activation of the tumor suppressing pathways p53/p2 $21^{\text {WAF } 1}$ and $p 16^{\text {INK } 4 a / p R B}$, as well as dramatic cellular changes including chromatin remodeling, metabolism switch, gene expression alterations and the secretion of inflammatory cytokines, growth factors, proteases and other molecules consisting the senescence-associated secretory phenotype (SASP). Among the numerous changes in chromatin structure occurring during senescence, the dynamics of heterochromatin is complex: while localized 
regions of heterochromatin known as senescence associated heterochromatic foci (SAHF) are formed in some types of senescent cells ${ }^{3}$, constitutive heterochromatin vanishes in most if not all types of senescence leading to its transcriptional derepression and contributing to aging ${ }^{4-6}$. Constitutive heterochromatin is found in all cell types at pericentromeres, telomeres/subtelomeres, retrotransposons and endogenous retroviruses and relies on the histone methyl transferases (SUVAR39H1/2 and SETDB1) to establish H3K9me3 chromatin domains covered by arrays of HP1 proteins ${ }^{7}$.

Although several effectors of heterochromatin remodeling have been identified ${ }^{8-12}$, how they are causally connected to senescence stressors remains unknown. Here, we investigate the relationship linking two key aging hallmarks, telomere shortening and constitutive heterochromatin loss, and ask how they are mechanistically connected during aging. For this, we designed a time-course experiment starting from young primary to replicative senescent cells that allowed us to uncover the central role of a p53-TRF2 axis driving a selective and severe constitutive heterochromatin dismantling, including the excision of pericentromeric DNA repeats triggering a cGAS-STING response in the cytosol. These results show how several aging hallmarks (here senescence, telomere shortening, DNA damage response, heterochromatin loss and inflammation) can be hierarchically connected. Our findings further argue that the predicted heterochromatin information loss observed during aging is not a random event but a programmed mechanism starting from TP53 activation.

\section{Pericentromeric DNA is selectively damaged during senescence}

To analyze the events leading to $\mathrm{PCH}$ alterations during senescence, we cultured lung primary fibroblast MRC-5 cells under hypoxic conditions (5\% oxygen) until they 
reached senescence and collected samples at consequent population doublings (PDs) (Figure S1A). We considered a culture as pre-senescent, when senescenceassociated beta-galactosidase (SA- $\beta$-Gal) positive cells started to accumulate while EdU positive cells decreased and a fully senescent culture when SA- $\beta$-Gal activity was detectable in all cells and EdU incorporation accounted for less than $1 \%$ of the cells. As reported previously ${ }^{13,14}$, telomeric DNA damage, as revealed by the colocalization of a telomeric peptide nucleic acid (PNA) probe with 53BP1 (TIFs- Telomere dysfunction-induced foci), gradually increase by subsequent PDs before the culture becomes fully senescent (Figure S1A). Roughly 5 PDs after the beginning of telomere uncapping, PCH DNA damage increased, as revealed by the colocalization of 53BP1 with a PNA FISH probe corresponding to Sat III DNA repeats (PIFs- pericentric dysfunction-induced foci) (Figure S1A). Strikingly, this increase in DNA damage is not evenly distributed throughout the chromosomes since no damage was detected at the alpha-satellite (alphoid) DNA sequences, constituting the major class of centromeric DNA repeats (CIFs-centromeric dysfunction induced foci) (Figure 1A). Thus, during replicative senescence, the accumulation of DNA damage outside telomeres appears selective for certain types of DNA repeats, e.g., pericentromeric but not centromeric repeats. To confirm and extend this finding, we performed chromatin immunoprecipitation experiments coupled to deep sequencing (ChIP-seq) with $\mathrm{y} 2 \mathrm{AX}$ antibodies. We analyzed highly repeated DNA sequences, largely underrepresented in the reference genome, by calculating their proportion in the ChIP-seq reads as normalized to input. This revealed a specific enrichment of reads containing Sat II, Sat III and telomere repeats, but not alphoid, rDNA and LINE-1 repeated sequences as compared to young cells (Figure 1B), confirming and extending the analyses by microscopy of TIFs, PIFs and CIFs in young and senescent cells (Figure 1A). 
Henceforth, we set to determine the mechanism responsible for the selective damage at PCH DNA during replicative senescence.

\section{DNA damage at pericentromeric heterochromatin precedes its decondensation} at senescence onset

It was previously reported that senescence is accompanied by $\mathrm{PCH}$ decondensation 5 , 6. In our kinetic analysis of senescence, the increase in PCH DNA damage slightly precedes decondensation, as estimated by measuring the diameter of Sat III PNA fluorescent speckles (Figures $1 \mathrm{C}$ and $\mathrm{S} 1 \mathrm{~A}$ ). As expected ${ }^{6}{ }^{15}, \mathrm{PCH}$ decondensation was accompanied by derepression of its transcription (Figure S1B). Echoing the lack of DNA damage at centromeres, there was no detectable increase in the diameter of the centromeric foci stained by an alphoid sequence PNA probe (Figures 1D and S1C). Instead, we observed a trend toward an increased number of smaller centromeric foci at senescence (Figure S1C), possibly reflecting chromatid cohesion defects ${ }^{16}$.

Next, we investigated whether the selective accumulation of PIFs and decondensation can be triggered by other senescence-inducing stressors. After four days of bleomycin treatment, the fully senescent culture exhibits a dramatic increase in global DNA damage, which is attenuated after ten days of bleomycin removal (Figure S1D). However, telomeric, as expected ${ }^{17,18}$, as well as PCH DNA damage persists, showing that, in senescent cells, both regions are sites of irreparable damage (Figure S1E). In hand with PCH DNA damages, PCH decondensation started 4 days after bleomycin treatment (Figure S1F). Centromere damage, in the other hand, remained low (Figure S1E).

The accumulation of damaged and decondensed $\mathrm{PCH}$ appears as a general hallmark of cellular senescence and organismal aging since we observed it in senescent cells 
of two other human diploid fibroblast cell lines, WI-38 and IMR-90 (Figure S2A) as well as in human dermal fibroblasts and mesenchymal stem cells (MSC) from old individuals (Figure S2B and S2C). In aging MSC, there is also an increase of DNA damage at telomeres but not at centromeres (Figure S2D), indicating that the selectivity of $\mathrm{PCH}$ and telomere damage observed in senescent fibroblasts in culture holds true during natural MSC aging.

\section{Selective pericentromeric heterochromatin dismantling occurring at senescence onset}

We further characterized the $\mathrm{PCH}$ alterations occurring at the senescence onset. In order to detect DNA double-strand breaks (DSBs) at $\mathrm{PCH}$, we used neutral comet assays coupled with specific PNA FISH probes. Compared to young cells, senescent cells had longer comet tails enriched in telomeric DNA and Sat III, but not in alphoid DNA sequences (Figure 2A). Thus, the DNA damage response (DDR) activation at $\mathrm{PCH}$ in senescent cells is likely to result from DSB formation. Then, we asked whether this high rate of DSBs led to illegitimate recombination events between pericentromeric DNA repeats by using chromatin-orientation FISH (CO-FISH) ${ }^{19}$. We found that the percentage of chromosomes with recombination events at PCH DNA increased in presenescent as compared to young cells (Figure 2B). This result also indicates that PCH alterations are detectable in dividing pre-senescent cells and thus is not an event specifically occurring when the cells stop dividing in the senescent state.

The high level of PCH DSBs and recombination events during senescence could result in gains or losses of DNA sequences. Thus, we measured PCH DNA length by a pulse field gel electrophoresis assay followed by Southern blotting of the resolved genomic DNA cut with HindllI restriction enzyme. This restriction cutting releases PCH DNA 
fragments of around $200 \mathrm{~kb}$, which were specifically hybridized with Sat II and Sat III probes. This restriction size decreased by roughly $50 \mathrm{~kb}$ in senescent cells (Figure $2 \mathrm{C}$ ). Such a DNA repeat shortening also occurs, as expected, for telomeric DNA (Figure S2E) but not for other repetitive elements such as Alu, rDNA, alphoid DNA or microsatellites (Figure 2C and S2F). Concomitantly, by combining DAPI and satellite III PNA staining, we observed a progressive increase in the number of cytoplasmic DNA specifically enriched in satellite III sequences during senescence establishment (Figure 2D).

Overall, these results show that the $\mathrm{PCH}$ is profoundly dismantled during senescence combining DNA damage and breaks, decondensation, transcriptional derepression, illegitimate inter-chromatid recombination, DNA loss and cytoplasmic DNA accumulation. The selectivity of this phenotype to $\mathrm{PCH}$ is shown by the absence of this combination of senescence-associated events at other highly repeated regions of the human genome, such as rDNA, LINE-1 and alphoid satellite repeats.

\section{Pericentric dismantling coincides with TRF2 decrease in pre-senescent cultures}

To examine the sequence of events linking telomere shortening to $\mathrm{PCH}$ dismantling, we measured the expression of the six shelterin subunits in the same samples with those used in the time points leading to the establishment of the senescent state (Figure $3 \mathrm{~A}$ and $3 \mathrm{~B}$ ). Only TRF2 and TPP1 were progressively downregulated to roughly $50 \%$ of their initial level. Impressively, the appearance of PIFs precisely correlates with the reduction in TRF2 and TPP1 expression (Figure 3B). Since TRF2 is known to bind PCH DNA and protect it against damage ${ }^{21}$, we asked whether this also holds true for TPP1. As expected, inhibition of TRF2 and TPP1 in young cells increased the frequency of TIFs, however, only TRF2 leads to a specific increase of 
PCH DNA damage (Figures S3A-C), making unlikely a direct role of TPP1 in senescence-associated PCH instability.

Then, we examined whether the lower levels of TRF2 in senescent cells have an impact on its association to PCH DNA. As quantified by ChIP, the TRF2 binding to PCH DNA was almost entirely lost in senescent cells, predicting an important impact of the senescence-associated TRF2 downregulation on PCH stability (Figure 3C). In contrast, approximately $50 \%$ of TRF2 remained bound to telomeres. Parallel ChIP experiments made with $\mathrm{yH} 2 \mathrm{AX}$ antibodies show, as expected, an increase in DNA damage at both telomeres and PCH (Figure 3C).

Overall, these results suggest that $\mathrm{PCH}$ integrity is specifically altered during replicative senescence establishment as a consequence of TRF2 downregulation.

\section{TRF2 decrease is sufficient to drive pericentromere dismantling}

Next, we asked whether TRF2 downregulation was sufficient to recapitulate the PHC dismantling phenotype observed at the onset of senescence. A 3-day downregulation of TERF2 expression in young MRC5 cells, specifically triggers the formation of DNA damage, DSBs and decondensation at PCH (Figures S3D-F). Then, we used a HeLa cell line containing an sh TERF2-inducible doxycycline system ${ }^{20}$. After 7 and 9 days of TRF2 inhibition, PCH decondensed (Figure 3D) and the length of the PCH DNA HindIII fragments progressively decreased by roughly $50 \mathrm{~kb}$ (Figure 3E), while PCH DNA became more recombinogenic as revealed by $\mathrm{CO}-\mathrm{FISH}$ (Figure $3 \mathrm{~F}$ ) and the number of cytoplasmic PCH DNA increased (Figure 3G). In contrast, cytoplasmic DNA composed of centromeric repeats was barely detectable (Figure 3SG), highlighting again the specificity of the effect of TRF2 downregulation on PCH dismantling. 


\section{TP53 activation leads to DNA damage specifically at pericentromeres}

Since degradation of TRF2 in pre-senescent cells was previously shown to be mediated by TP53-dependent Siah1 upregulation ${ }^{21}$, we asked whether TP53 activation is involved in PCH dismantling. As expected, inhibition of TP53 counteracted the downregulation of TRF2 in pre-senescent cells (Figure 4A). Impressively, even though total DDR activation increased upon TP53 depletion (Figure 4B), PCH DNA damage significantly decreased in pre-senescent (PD 60) and senescent cells (PD 67) as compared to control cells, while the levels of telomere damage remained unchanged (Figure 4B and 4C). PCH opening was also prevented upon TP53 depletion (Figure 4D). These results show that TP53 activation leads to DNA damages and decondensation specifically at $\mathrm{PCH}$.

In MRC- 5 cells exposed to bleomycin for 4 days, there was also a correlation between the increased TP53 expression and gradual reduction of TRF2 levels (Figure S4A), while depletion of p53 restored the levels of TRF2 (Figure S4B). In agreement with this result, treating young MRC5 cells with the MDM2-p53 interaction inhibitor, Nutlin-3a, led to TRF2 loss with an augmentation of PCH DNA damage and decondensation (Figures S4C and S4D). Therefore, the TP53-dependent control of TRF2 expression and PCH instability is not limited to cells experiencing telomere shortening.

\section{TRF2 downregulation is necessary to drive pericentromeric dismantling at senescence onset}

Next, we asked whether the TP53-dependent TRF2 downregulation is necessary for the senescence-associated PCH dismantling phenotype. To this end, we ectopically expressed TRF2 from PD 50 until senescence, in order to counteract its TP53dependent degradation (Figure S5A). As negative controls, we ectopically expressed 
TRF1, which is not required for $\mathrm{PCH}$ stability, and $\mathrm{TRF}^{\triangle \mathrm{B}}$, a separation of function form of TRF2 preserving its telomere capping properties but unable to protect $\mathrm{PCH}^{22}$. Cells that ectopically expressed TRF2 and TRF2 ${ }^{\triangle B}$, but not TRF1, bypassed the proliferative capacity of the control culture, lengthened it by approximately 5 PDs before entry into a second senescent state (Figure S5A). These results are in accordance with a previous work showing that TRF2 overexpression delays senescence ${ }^{23}$. The second senescence arrest of MRC-5 cells overexpressing TRF2 corresponds to $\mathrm{p} 16^{\mathrm{CDKN} 4 a}$ activation in contrast to replicative senescent cells mostly inducing p21 WAF1 (Figure S5B). Importantly, ectopic expression of TRF2, but neither of TRF1 nor TRF2 ${ }^{\triangle B}$, prevents PCH DNA damage and PCH decondensation (Figure 5A). Moreover, the PCH DNA length is restored by the ectopic expression of TRF2 during senescence (Figure 5B). The low amount of centromeric DNA damages at senescence is not affected by TRF2 dosage (Figure S5C), illustrating again the PCH-specificity of the TRF2 role at senescence.

These results also reveal that $\mathrm{PCH}$ dismantling does not trigger replicative senescence arrest since $\mathrm{TRF}^{\mathrm{AB}}$ ectopic expression does not rescue $\mathrm{PCH}$ stability but bypass senescence as TRF2. Unexpectedly, ectopic expression of TRF2 or TRF2 ${ }^{\triangle B}$ did not restored telomere protection (Figure 5C); a result that cannot be explained by a telomere DNA lengthening effect (Figure S5D). Of note, ectopic expression of TRF2 in bleomycin-induced senescent cells also exhibited a decrease in PCH DNA damage and decondensation while telomere, centromere and overall cell damage remained unchanged (Figures S5E and S5F), excluding a general blunting effect of TRF2 overexpression on DDR activation.

Overall, these results show that the TP53-dependent TRF2 decline occurring during replicative senescence or upon genotoxic stress is responsible for a specific $\mathrm{PCH}$ 
dismantling phenotype.

The ATM DNA damage response triggered by TRF2 downregulation leads to pericentromeric decondensation

Next, we envisaged the possibility that TRF2 downregulation triggers $\mathrm{PCH}$ decondensation through ATM activation. The pharmacological inhibition of ATM (KU55933) prevented PCH decondensation in MRC-5 and HeLa TRF2-compromised cells (Figures $5 \mathrm{D}$ and $\mathrm{S} 6 \mathrm{~A}$ ) showing that $\mathrm{ATM}$ activation is required for the $\mathrm{PCH}$ decondensation upon TRF2 downregulation. The fact that the quantity of $\mathrm{H} 3 \mathrm{~K} 9 \mathrm{me} 3$ at $\mathrm{PCH}$ was not altered either by TRF2 loss or overexpression (Figures S6B and S6C) suggests that the effect of TRF2 loss and ATM activation on heterochromatin structure is acting above the nucleosomal level. Thus, we examined the hypothesis that the association of two key heterochromatin factors, KAP1 and Lamin B1 (LMNB1) ${ }^{5,24}$, to $\mathrm{PCH}$ is controlled by TRF2 and ATM at the onset of senescence since they are downregulated during senescence ${ }^{8,12}$. We show that the loss of KAP1 or LMNB1 in young MRC5 cells leads to PCH decondensation in an ATM-dependent manner and loss of PCH signal (Figure S6D and S6E). Notably, the senescence-coupled reduction of KAP1 and LMNB1 localization at PCH, was reversed by the ectopic expression of TRF2 (Figure 5E). We conclude that the ATM activation triggered by TRF2 loss during senescence controls the release of KAP1 and LMNB1 from $\mathrm{PCH}$ and its subsequent decondensation. 
Interestingly, the cytoplasmic PCH DNA is selectively stained with the immune sensor cyclin GMP-AMP synthase (cGAS) (Figure S6F), in agreement with a previous report showing that CGAS preferentially binds Sat III DNA ${ }^{25}$. This, together with the fact that the ectopic expression of TRF2 in senescent cells reduced the proportion of cytoplasmic PCH DNA (Figure S6F), suggest a contribution of the TP53-TRF2-PCH axis on the pro-inflammatory properties of senescent cells. To test this hypothesis, we asked whether an immunological transcriptional signature depends upon TRF2 expression levels. The transcriptome of senescent cells with a restored level of TRF2 show, as compared to the one of control senescent cells, an underrepresentation in pathways related to the immune system such as the interferon alpha/beta signaling pathway and an overrepresentation in cell-cycle pathways (Figure 5F). Notably, the expression of five prominent interferon-stimulated genes, IFIT2, IFT3, OASL, TRIM25 and ISG15, is downregulated upon TRF2 overexpression.

Overall, we conclude that the programmed TP53-dependent TRF2 decrease during senescence, triggers a selective PHC dismantling process that increases the amount of cytoplasmic cGAS-associated PCH DNA and activates an interferon response.

\section{Senescence-associated pericentromeric heterochromatin dismantling as a mechanism of chromosome rearrangement in cancer cells}

Since cancer cells can derive from senescent cells that escaped cell cycle checkpoints 26, we asked whether the senescence-associated PCH dismantling could promote the aberrant chromosome rearrangements involving heterochromatin that are observed in numerous cancer cells ${ }^{27-29} 30$. Thus, we used a model of senescence escape by transducing fully replicative senescent cells with a shp2 $21^{\mathrm{CIP} 1}$-expressing lentivirus ${ }^{31}$. The control senescent cells began to divide seven days post infection (DPI) with no 
indication of clonal growth whereas the shp21 ${ }^{\mathrm{CIP} 1}$ cultures were expanding homogeneously (Figure 6A). We co-transduced post-senescent shp21 ${ }^{\mathrm{CIP} 1}$ cells with TRF2, hTERT or an empty lentivirus vector. Importantly, cells expressing an empty vector entered back into senescence after 9 PDs in culture, while the cells expressing the full length TRF2 continued to divide for $\sim 12.5$ PDs after viral infection. While the global DDR remained nearly constant (Figure 6B), the number of PCH DNA damages markedly decreased in post-senescent cells overexpressing TRF2 at 10 DPI (Figure $6 \mathrm{C})$, but the levels of TIFs remained high reflecting the continuous telomere shortening in these cells (Figures 6B and S7A). Remarkably, like in pre-senescent cells, PCH DNA loss and decondensation are reverted upon an ectopic expression of TRF2 in postsenescent cells (Figure 6C and S7B). The hTERT-expressing post-senescent cells divide continuously with restored telomere length, TRF2 expression as well as $\mathrm{PCH}$ DNA damage, decondensation and content (Figures 6B, 6C and S7A-C). These results are in agreement with a reversal of the TP53-dependent TRF2 downregulation upon telomere lengthening. Finally, we depleted TRF2 in hTERT expressing post-senescent cells to determine whether TRF2 is directly involved in the stability of PCH DNA. As expected, TRF2 depletion led to an increased number of PIFs, TIFs and Sat III decondensation (Figure 6B and 6C).

Finally, using multicolor fluorescence in situ hybridization (M-FISH) in combination with inverted DAPI banding, we identified in post-senescent cells chromosomal breakpoints involving primarily heterochromatic and telomeric regions (Figures 6D and S7D). Notably, chromosomal aberrations involving heterochromatin regions were rescued by TRF2 or hTERT co-transductions while only hTERT rescued telomeric aberrations.

These results show that, in case of checkpoint failure and return to growth of senescent cells, the consequence of the $\mathrm{PCH}$ dismantling is the formation of chromosome 
rearrangements involving heterochromatin, a classical cytogenetic feature of human chromosome aberrations in cancer cells.

\section{Discussion}

Here we uncover a senescence mechanism driving heterochromatin dismantling in response to TP53 activation which is dependent on the telomeric protein TRF2. This reveals a new function of this protein as a pericentric heterochromatin disassembler. Specifically, we found that the integrity of pericentromeric heterochromatin $(\mathrm{PCH})$ is markedly and specifically altered in senescent cells, combining DNA damage, decondensation, elevated sister chromatid recombination, repetitive DNA loss and accumulation of cytoplasmic PCH DNA specifically associated to cGAS. The PCH dismantling occurs early when the cells enter into senescence and can be detected in pre-senescent cultures. Its specificity is demonstrated by the preservation of the integrity of alphoid centromeric chromatin and other repeated heterochromatic regions when $\mathrm{PCH}$ becomes dismantled. We elucidated the mechanism driving these dramatic changes in heterochromatin integrity as being a consequence of TP53 activation leading to TRF2 downregulation and $\mathrm{PCH}$ dismantling. Indeed, the senescenceassociated PCH dismantling phenotype can be prevented by TP53 inhibition or by an ectopic expression of TRF2 counteracting its TP53-dependent downregulation. Remarkably, the roughly half dosage of TRF2 induced by TP53 activation, is sufficient to almost fully abolish its association to $\mathrm{PCH}$ DNA, in contrast to telomere binding that diminished by about $50 \%$. This differential impact of the reduced TRF2 levels between telomeric and PCH DNA can be explained by the mass-action law principle, predicting that a limited variation in protein concentration has a greater impact on low-affinity binding sites, as expected for PCH DNA, than high-affinity sites, as telomeres. Hence, 
it is revealed that the TP53-dependent TRF2 downregulation exerts more important impact on $\mathrm{PCH}$ stability than at telomeres.

These results highlight the biological importance of the role of the TRF2 association to heterochromatin, which we previously showed to be required for the progression of the replication fork through this difficult-to-replicate regions in transformed cells ${ }^{22}$. Since $\mathrm{PCH}$ dismantling is already detected in presenescent cultures, the divisions of presenescent cells with a reduced level of TRF2 are likely to lead to the accumulation of $\mathrm{PCH}$ replicative damages. Of note, the $\mathrm{PCH}$ dismantling observed in bleomycin-treated cells also depends upon a TP53-dependent TRF2 downregulation and occurs in cellcycle arrested cells due to the immediate checkpoint activation upon drug treatment. This implies that TRF2 must also have protective roles at $\mathrm{PCH}$ independently of replication. A likely explanation is that TRF2 has a general role in preventing ATM activation at $\mathrm{PCH}$ at DSB repair since TRF2 was reported to bind to accidental DSBs 32 and to favor homologous recombination genome wide ${ }^{33}$. A PCH protective role of TRF2 both during replication and as part of the normal PCH DNA repair is supported by the fact that the $\mathrm{PCH}$ dismantling is not restored upon the overexpression of a truncated form of TRF2 lacking the basic $\mathrm{N}$-terminal domain $\left(\mathrm{TRF}^{\triangle \mathrm{B}}\right.$ ), a mutant form previously reported to be impaired in both $\mathrm{PCH}$ replication ${ }^{22}$ and $\mathrm{DSB}$ signaling ${ }^{32}$. The $\mathrm{PCH}$ dismantling triggered by TRF2 downregulation in senescent cells is ATM dependent and involves the association of KAP1 and Lamin B1 (LMNB1) to PCH. This, together with the fact that PCH dismantling upon KAP1 or LMNB1 downregulation is ATM dependent, indicate that TRF2 controls, in an ATM-dependent manner, the higher-order organization of PCH shaped by KAP1 and LMNB1. Overall, our results delineate the following model of how TP53 activation drives PCH dismantling (see model in Figure S7E). As a consequence of senescence stressors, such as telomere 
shortening or genotoxic exposure, TP53 activation decreases TRF2 expression, which triggers DNA damage selectively at $\mathrm{PCH}$ resulting in ATM activation. This leads to $\mathrm{PCH}$ decondensation through the release of KAP1 and LMNB1. This is in agreement with the fact that KAP1 is phosphorylated by ATM in case of heterochromatin damage leading to local opening and repair ${ }^{24}$. This also indicates that TRF2 controls the association of LMNB1 to $\mathrm{PCH}$. This might result from a direct TRF2-LMNB1 interaction that is currently under investigation (Mendez-Bermudez et al, unpublished) and previously suggested for the TRF2 ortholog of the parasite Entamoeba histolytica ${ }^{34}$. Upon TRF2 downregulation, there is a substantial PCH dismantling leading to the assumption that the DNA damages are too important to be normally repaired. The resulting $\mathrm{PCH}$ decondensation and illegitimate repair are expected to lead to sister chromatid recombination events resulting in PCH DNA excision and accumulation in the cytoplasm (see model in Figure S7E).

The PCH dismantling due to TRF2 downregulation does not cause the entry into senescence since TRF2 ${ }^{\triangle B}$ overexpression does not rescue $\mathrm{PCH}$ dismantling while it is sufficient to bypass the senescence checkpoint, like full length TRF2 (Figure 5A). This, together with our finding that telomere protection at the onset of replicative senescence is insensitive to global TRF2 dosage, lead us to conclude that TRF2 prevents replicative senescence arrest independently of telomere and $\mathrm{PCH}$ protection.

If the senescence-associated PCH dismantling does not cause cell cycle arrest at the onset of senescence, it plays other important roles in the senescence program. Indeed, we showed that it facilitates the activation of an interferon response by favoring the accumulation of cytoplasmic PCH DNA prone to activate the cGAS-STING pathway (Figure 5F). This mechanism appears distinct from the activation of the L1 retrotransposons leading to an interferon response in late senescent cells ${ }^{9}$ since the 
dismantling phenotype triggered by TRF2 downregulation occurs earlier, at senescence onset, and we did not detect an effect of TRF2 downregulation on L1 integrity. We also unveiled that $\mathrm{PCH}$ dismantling can result in aberrant heterochromatin rearrangements in case of senescence checkpoint failure. This suggests that aging, by generating senescence-associated $\mathrm{PCH}$ dismantling, favors, in case of checkpoint failure, complex chromosome rearrangements associated with cancer, providing a novel mechanism linking cell senescence to oncogenesis.

We discover here how the activation of TP53 in response to telomere shortening or genotoxic stress leads to a profound dismantling of the $\mathrm{PCH}$ compartment of our genome via the downregulation of the key telomere protein TRF2. This p53-TRF2- axis is likely to play an important role during aging, since we observed age-dependent signs of selective $\mathrm{PCH}$ dismantling in various human cell types, including MSCs and skin fibroblasts. We anticipate that interventions stabilizing TRF2 will prevent heterochromatin dismantling during aging thus offering a valuable strategy to prevent age-related diseases, including cancer.

\section{Acknowledgments}

The IRCAN's Molecular and Cellular Core Imaging (PICMI) is supported by "le Cancéropole PACA, la Région Provence Alpes-Côte d’Azur, le Conseil Départemental 06", and INSERM. The IRCAN's GenoMed, the Genomic Core Facility at IRCAN is supported by le Conseil Départemental 06, Aviesan and INSERM. This work was supported by the cross-cutting INSERM program on aging (AGEMED), "Investments for the Future" LABEXSIGNALIFE (reference ANR-11-LABX-0028-01), the "Fondation ARC pour la recherche contre le cancer", INCa (project REPLITOP) and the ANR (project TELOCHROM). Work in the JY laboratories was supported by the National 
Natural Science Foundation of China (grant numbers 81971312, 91749126, 81911530241,81871549 and 81671900), the Program of Shanghai Academic/Technology Research Leader (grant number 19XD1422500) and the Shanghai Municipal Education Commission (Oriental Scholars Program, 2019).

\section{Author Contributions}

Conceptualization, A.M-B., J.Y., E.G.; Methodology, A.M-B.; Software, M.P., F.T., O.C.; Formal Analysis, A.M-B., M.P., L.L., S.G.; Investigation, A.M-B., L.L., C.M.L., V.C., J.N.; Resources, J.X., C.A.; Writing-Original Draft, A.M-B., J.Y., E.G.; Funding Acquisition, J.Y., Y.L., E.G.

\section{Declaration of Interests}

The authors declare no competing interests. 


\section{Materials and Methods}

\section{Cell lines}

Human primary MRC-5 and WI-38 cells were obtained from the ATCC. IMR-90 cells were a gift from the Jean-Marc Lemaitre lab, while the shTERF2-inducible HeLa cell line was a gift from the Joachim Lingner lab. All cell lines used in this study were grown in DMEM supplemented with $10 \%$ fetal calf serum. Primary cell lines were grown at $5 \%$ oxygen. All cell lines were routinely tested for mycoplasma contamination.

\section{Antibodies}

The following primary antibodies were used for immunofluorescence: anti-53BP1 (Novus Biologicals, NB100-305), anti-TRF2 (Novus Biologicals IMG-124A), anti-pATM (ser1981) (Cell Signaling Technology, 4526), anti-Kap1 (abcam, ab22553), anti-Lamin B1 (abcam, ab16048), anti-H3K9me3 (abcam, ab8898) and anti-cGAS (D1D3G) (Cell Signaling Technology, 15102). For Western blotting: anti-TRF2 (Novus Biologicals, NB110-57130), anti-TRF1 (Santa Cruz Biotechnology, sc-6165), anti-Pot1 (Abcam, ab21382), anti-TPP1 (Abcam, ab195234), anti-TIN2, anti-RAP1 (Bethyl, A300-306A), anti-p53 (Abcam, ab131442), anti-actin, anti-GAPDH (Novus Biologicals, NB10056875), anti-p21 ${ }^{\mathrm{CIP1}}$ (Abcam, ab16767), anti-p16 ${ }^{\mathrm{INK} 4 \mathrm{~A}}$ (Abcam, ab 554079). Antibodies used for ChIP and IP experiments: anti-yH2A.X (Abcam, ab2893), anti-H3K9me3 (Upstate, 07-442). Secondary antibodies were: goat anti-rabbit Alexa 488 antibody (111-545-144; Jackson Immunodetect), goat anti-mouse Alexa 488 antibody (115-545146; Jackson Immunodetect), HRP goat anti-mouse IgG (Vector Laboratories, PI2000) and HRP goat anti-rabbit IgG (Vector Laboratories, PI-1000).

\section{Senescence and proliferation assay}


To detect senescence-associated $\beta$-galactosidase (SA- $\beta$-Gal) activity in cultured cells, the Senescence Detection Kit (Abcam, ab65351) was used according to the manufacturer's instructions. To assess for cellular proliferation, $10 \mu \mathrm{M}$ EdU was added to the culture for $24 \mathrm{~h}$ at $1 \mu \mathrm{M}$ final concentration. EdU was detected using the ClickiT EdU Alexa Fluor 647 Imaging Kit (Thermo Scientific, C10340).

\section{Comet-FISH assay}

For each condition, around 5000 cells were embedded in $0.5 \%$ low-melting agarose dissolved in 1X PBS. The suspension was immediately laid onto comet slides (4250200-03, Trevigen). Agarose was allowed to solidify at $4^{\circ} \mathrm{C}$ for $20 \mathrm{~min}$ and the comet slides were then immersed in pre-chilled lysis solution $(2.5 \mathrm{M} \mathrm{NaCl}, 100 \mathrm{mM}$ EDTA, 10 $\mathrm{mM}$ Tris and $1 \%$ Triton, $\mathrm{pH} 10$ ) at $4^{\circ} \mathrm{C}$ for $90 \mathrm{~min}$ in the dark. Next, the comet slides were placed in a horizontal electrophoresis unit and allowed to equilibrate in 0.5X TBE buffer $(\mathrm{pH} 8)$ for $5 \mathrm{~min}$ at $4^{\circ} \mathrm{C}$ in the dark. The migration was performed at $40 \mathrm{~V}$ for 20 min. The slides were then placed in $100 \%$ ethanol for 30 min at $4{ }^{\circ} \mathrm{C}$ and denatured in $0.5 \mathrm{M}$ of $\mathrm{NaOH}$ for $25 \mathrm{~min}$. Finally, the slides were dehydrated in an ascending series of ethanol solutions (50\%, $70 \%$, and $100 \%$ for 5 min each) and air-dried.

Hybridization with Sat III, telomere and centromere PNA probes (Panagene) was performed at RT for at least $2 \mathrm{~h}$ in $70 \%$ formamide, $10 \mathrm{mM}$ Tris $\mathrm{pH} 7.2$ and $1 \%$ blocking solution (Roche). Following hybridization, the slides were washed with a solution containing $50 \%$ formamide and $10 \mathrm{mM}$ Tris $\mathrm{pH} 7.2$ for $30 \mathrm{~min}$, followed by a 10 min wash in a solution of $50 \mathrm{mM}$ Tris $\mathrm{pH} 7.5,150 \mathrm{mM} \mathrm{NaCl}$ and $0.05 \%$ Tween-20. Slides were left to air dry for $30 \mathrm{~min}$ and the DNA was stained with either YOYO-1 or propidium iodide for $10 \mathrm{~min}$.

For analysis, the tail moment (tail length $x$ DNA in the tail / total DNA) was recorded for each comet (60-80 cells) using the Tritek Comet Score freeware. The PNA signal was 
visualized with a Zeiss epi-fluorescence microscope. Student's t-test was used for statistical analysis.

\section{Genomic DNA extraction and Southern blotting}

In brief, high molecular weight DNA was extracted by lysing the cells in a $100 \mathrm{mM}$ Tris$\mathrm{HCl} \mathrm{pH} 7.5,100 \mathrm{mM} \mathrm{NaCl}, 10$ mM EDTA, 1 \% Sarkosyl solution. An initial incubation of $20 \mathrm{~min}$ with $50 \mu \mathrm{g} / \mathrm{ml}$ RNase was followed by $500 \mu \mathrm{g} / \mathrm{ml}$ proteinase $\mathrm{K}$ for $6 \mathrm{~h}$ at 55 ${ }^{\circ} \mathrm{C}$. The samples were then subjected to phenol/chloroform extraction and ethanol precipitation. DNA was digested with Hindll, and about $2 \mu \mathrm{g}$ was electrophoresed in a CHEF-DR III pulse-field electrophoresis apparatus (Bio-Rad Laboratories) in recirculating $0.5 \mathrm{X}$ TBE buffer at $14{ }^{\circ} \mathrm{C}$. Electrophoresis was performed for $16 \mathrm{~h}$ using $6 \mathrm{~V} / \mathrm{cm}$ and 50-90 s switch time. The gel was rinsed and stained with ethidium bromide to visualize the DNA and Southern blotting was carried out using standard methods. The Southern blot membrane (Hybond $\mathrm{N}_{+}, \mathrm{GE}$ Healthcare) was hybridized to ${ }^{32} \mathrm{P}-$ adCTP-labeled probes in Church buffer at $65^{\circ} \mathrm{C}$. The signal was visualized using a phosphor imager scanner (Typhoon; GE Healthcare) and analysis performed using Image Quant TL software (GE Healthcare).

\section{Chromatin Orientation Fluorescence in Situ Hybridization}

CO-FISH was carried out as described previously ${ }^{19}$ with some modifications. Briefly, a mix of BrdU:BrdC (3:1) was added to the media of MRC-5 for $20 \mathrm{~h}$. Next day, metaphase spreads were generated using standard methods. Slides containing metaphase spreads were treated with $0.5 \mathrm{mg} / \mathrm{ml}$ RNaseA for $10 \mathrm{~min}$ at $37{ }^{\circ} \mathrm{C}$ and stained with $0.5 \mathrm{ug} / \mathrm{ml}$ Hoechst 33258 for $15 \mathrm{~min}$ at room temperature. Then, slides were placed in a plastic tray containing 2x SSC and exposed to $365 \mathrm{mn}$ UV light for 30 min. Incorporated BrdU/BrdC was removed with $800 \mathrm{U}$ of exonuclease III (Promega) followed by dehydration with increasing concentrations of ethanol. Hybridization of Sat 
III strand specific PNA probes (Су3-OO-TTCCATTCCATTCCATTCCA and FAM-OOTGGAATGGAATGGAATGGAA) was performed sequentially for $2 \mathrm{~h}$ each. The removal of unspecific PNA probe was done by washes with $70 \%$ formamide, $10 \mathrm{mM}$ Tris pH 7.2 and $50 \mathrm{mM}$ Tris $\mathrm{pH}$ 7.5, $150 \mathrm{mM} \mathrm{NaCl}, 0.05 \%$ Tween. Finally, cells were preserved in a mounting solution with DAPI (Vectashield, Vector Laboratories).

\section{Multicolor FISH (M-FISH)}

Chromosome spreads were prepared by arresting actively dividing MRC-5 cultures using $50 \mathrm{ng} / \mathrm{ml}$ colcemid (KaryoMAX, Invitrogen) for 2 hours at $37^{\circ} \mathrm{C}$. Afterwards, trypsinized cells were incubated with hypotonic solution $(75 \mathrm{mM} \mathrm{KCl})$ for 15 minutes at $37 \stackrel{\circ}{\mathrm{C}}$, fixed with ice-cold methanol:glacial acetic acid (3:1), and spread on slides. mFISH was performed using the 24XCyte kit (MetaSystems Probes) according to manufacturer's instructions. Stained metaphase chromosomes were visualized on the Zeiss Axiovert Z2 epi-fluorescent microscope and analyzed using the metasystem ISIS software.

To identify "cryptic" centromeric and $\mathrm{PCH}$ chromosomal rearrangements, we destained M-FISH chromosome preparations with multiple washes in PBS at $37^{\circ} \mathrm{C}$. We consequently applied dual color FISH, using an alpha-satellite pancentromeric probe labelled with FITC and a Satellite III probe labelled with Cy3, on the same mitotic plates examined by M-FISH and Inverted-DAPI Banding, retrieved by pre-recording slide's co-ordinates.

\section{Microsatellite instability}

Microsatellite instability was assayed by PCR amplification using the Platinum hot start PCR master mix (ThermoFisher). The PCR products were loaded into a microfluidic chip for DNA (Agilent DNA $1000 \mathrm{kit}$ ) and the analysis performed with the 2100 Bioanalyzer instrument (Agilent). 


\section{Lentivirus infection and siRNA transfection.}

siTRF2, siKap1 and siLMNB1 (On-Target Plus SMARTpool) and siControl (D-001810) were purchased from Dharmacon. Transient transfections were performed with Dharmafect1 transfection reagent (Dharmacon) for $72 \mathrm{~h}$.

Lentiviruses were produced by transient calcium phosphate transfection of 293T cells with the virus packaging plasmids, p8.91 and pVSVg, as well as with the lentiviral expression vector that contained the sequence of interest. Titration was performed approximately 10 days after infection using puromycin $(1 \mu \mathrm{g} / \mathrm{ml})$ to select clones. The pLKO-shp21 1 IIP1

(shp21:CCGGCCGCGACTGTGATGCGCTAATCTCGAGATTAGCGCATCACAGTC GCGGTTTTTG) was purchased from Sigma. Efficiency of each shRNA and siRNA was checked routinely by RT-qPCR or western blotting.

\section{Real-time qPCR}

qPCR was used to determine the efficiency of siRNA downregulation and for ChIP validation. For siRNA inhibition, total RNA (RNeasy Mini Kit, Qiagen) was reverse transcribed using the High-Capacity RNA-to-cDNA kit (Thermo Scientific). qPCR was performed using an Applied StepOnePlus system (Life Technologies) with SYBR green master mix (Roche, 4913914 001). Only siRNA transfections giving rise to a reduction of $\geq 75 \%$ were used in this study.

\section{Immunofluorescence-FISH}

Cells were grown on glass coverslips at about $70-80 \%$ confluency and fixed in $3.7 \%$ formaldehyde. Immunofluorescence coupled with FISH was performed as previously described ${ }^{21}$.

To perform immunofluorescence-FISH in paraffin-embedded tissue sections, the samples were incubated twice with xylene for $5 \mathrm{~min}$, followed by washes in 
progressively decreasing concentrations of ethanol (100\%, $90 \%, 70 \%$ and $40 \%)$ of 5 min each, and then washed in 1X PBS for another 5 min. Next, antigen unmasking was carried out in $10 \mathrm{mM}$ sodium citrate, $0.05 \%$ Tween- $20 \mathrm{pH} 6$ solution for $45 \mathrm{~min}$ at $95 \stackrel{\circ}{ }{ }^{\circ}$. The sections were dehydrated in $95 \%$ ethanol for 3 min and air-dried follow by PNA hybridization.

\section{Image acquisition and analysis}

Images were acquired with a Zeiss LSM-888 inverted confocal laser scanning microscope. A minimum of $18 \mathrm{z}$-planes were acquired with a $63 \mathrm{X}$ oil immersion objective (Plan-Apochromat 63x/1.4 Oil DIC). Images were analyzed with the ZEN 2009 (Zeiss).

\section{Western blotting}

Total protein extracts were obtained using ice-cold RIPA buffer for 30 min. Samples were separated by SDS-PAGE electrophoresis using NuPAGE Mini gels (Life Technologies). Proteins were transferred onto Protran BA 85 nitrocellulose membranes (Whatman, GE Healthcare) followed by at least $1 \mathrm{~h}$ blocking with PBST in $5 \%$ skim milk. Hybridization with primary antibodies was performed overnight at $4 \stackrel{\circ}{\circ}$ followed by $1 \mathrm{~h}$ incubation with secondary horseradish peroxidase conjugated antibodies. Membranes were developed using the Luminata Forte HRP substrate (Millipore) and exposed in the Fusion Solo apparatus (Vilbert Lourmat).

\section{Native chromatin immunoprecipitation}

Native ChIP was performed as described in Rai and Adams (2016) ${ }^{35}$ with some modifications. Briefly, cells were grown at about $70 \%$ confluency, scraped in cold PBS to detach them and resuspended in MLB: $\mathrm{H}_{2} \mathrm{O} 1: 4$ buffer (MLB; $50 \mathrm{mM}$ Tris $\mathrm{pH} 7.5 ; 150$ $\mathrm{mM} \mathrm{NaCl} ; 0.5 \% \mathrm{NP} 40$ and $15 \mathrm{mM} \mathrm{MgCl}$ ) supplemented with proteinase inhibitors. The mix was immediately transferred to Eppendorf tubes and kept on ice for $10 \mathrm{~min}$ 
and centrifuged for $3 \mathrm{~min}$ at $300 \mathrm{xg}$ at $4 \stackrel{\circ}{\circ}$. The supernatant was removed, and the pellet resuspended in $400 \mu \mathrm{l}$ of BB buffer (50 mM Tris pH 7.5; $300 \mathrm{mM} \mathrm{NaCl} ; 0.5 \%$ $\mathrm{NP} 40$ and $2.5 \mathrm{mM} \mathrm{MgCl} 2$ ) with proteinase inhibitors and $120 \mathrm{U}$ of Benzonase (Sigma, E1014). The solution was incubated on ice for $30 \mathrm{~min}$ and $40 \mu \mathrm{l}$ were taken for DNA quantification followed by a short centrifugation step of 3 min at $300 \times \mathrm{xg}$ at $4 \stackrel{\circ}{\circ}$. The supernatant was transferred to a clean Eppendorf tube containing an equal volume of DB solution (50 mM Tris pH 7.5; $300 \mathrm{mM} \mathrm{NaCl} ; 0.5 \%$ NP40 and $15 \mathrm{mM}$ EDTA) with proteinase inhibitors. Next, $150 \mu \mathrm{l}$ of magnetic beads (Dynabeads, Life Technologies) with the desired antibody were added to the mix for $6 \mathrm{~h}$ at $4{ }^{\circ} \mathrm{C}$. Previously, the magnetic beads were washed 3 times with 1 X PBS and $0.5 \%$ bovine serum albumin followed by the addition of $5 \mu \mathrm{g}$ of the desired antibody.

Next, the mix containing the immunoprecipitated chromatin was washed $3 x$ with a solution containing $50 \mathrm{mM}$ Tris $\mathrm{pH}$ 7.5; $150 \mathrm{mM} \mathrm{NaCl} ; 0.5 \%$ NP40 and $5 \mathrm{mM}$ EDTA, followed by 3 washes of a solution containing $50 \mathrm{mM}$ Tris $\mathrm{pH} 7.5 ; 300 \mathrm{mM} \mathrm{NaCl} ; 0.5$ $\%$ NP40 and 5 mM EDTA. Finally, the beads were recovered, and the chromatin was eluted with a $1 \% \mathrm{SDS}, 0.1 \mathrm{M} \mathrm{NaHCO}_{3}$ solution. The solution was treated with RNase (10 $\mathrm{mg} / \mathrm{ml}$ for $20 \mathrm{~min}$ ), proteinase $\mathrm{K}(10 \mathrm{mg} / \mathrm{ml}$ for $1 \mathrm{~h}$ at $50 \stackrel{\circ}{\circ}$ ) followed by phenolchloroform purification and ethanol precipitation. Quantification of immunoprecipitated DNA was performed with the Qubit HS kit (Thermo Scientific).

\section{Slot blotting}

The DNA obtained from native ChIP experiments was denatured $(0.5 \mathrm{M} \mathrm{NaOH}, 2 \mathrm{M}$ $\mathrm{NaCl}$ and $25 \mathrm{mM}$ EDTA) and blotted onto nylon membranes using a slot blot apparatus, crosslinked, and hybridized with radioactively labeled probes. The membranes were exposed onto phosphor imager screens and the signal intensity was quantified with ImageQuant software. 


\section{ChIP sequencing and analysis}

YH2AX ChIP-seq library preparation was performed using the MicroPlex Library Preparation kit v2 (Diagenode, C05010012) while single-end sequencing (read length: 75 bp) was performed using the Illumina Nextseq 500/550 High output v2.5 system according to the manufacturer's instructions. Two biological replicates per condition were performed ( $\sim 45-60$ million reads per sample). Reads were trimmed and cleaned using fastP software ${ }^{36}$ and deduplicated using Clumpify software from the BBmap package (available

at

https://github.com/BiolnfoTools/BBMap/blob/master/sh/clumpify.sh). Reads were mapped on the GRCh38 human genome assembly using Bowtie2 with default parameters ${ }^{37}$. Broad peak calling was performed using EPIC2 program (v0.0.36) ${ }^{38}$ with the following settings: --genome hg38; --keep-duplicates; --mapq 0. Finally, following ENCODE guidelines ${ }^{39}$, peaks within blacklisted regions were removed. Peaks profiles were generated using the "Score" column from EPIC2 output and bedGraphToBigWig tool from UCSC.

Motifs for different repeat elements Sat III, Sat II, telomeric, alphoid, rDNA, LINE1, Alu repeats) were searched using a home-made Python script, in raw fastq files, without considering mismatches and including reverse complement motifs. IP samples counts were normalized to their corresponding Input sample count.

\section{RNA sequencing}

Total RNA was extracted using the RNeasy mini kit (Qiagen). Paired-end sequencing (read length: 2x $150 \mathrm{bp}$ ) was performed by NovoGene using an Illumina sequencer. Two biological replicates were performed for senescent cells transduced with an empty vector and three biological replicates with TRF2 expressing cells (between 30 and 50 million reads per sample). Raw RNA-seq reads were trimmed using Trimmomatic 
(v0.39) ${ }^{40}$ and the minimal read length was set to $35 \mathrm{bp}$. Read mapping and genome index building were performed using STAR (v2.6.1d) ${ }^{41}$. Reads were mapped to the human genome assembly (GRCh38) using the -quantMode GeneCounts option. Differential expression analysis was performed using the DESeq2 R package ${ }^{42}$.

\section{Statistics}

GraphPad Prism 5 software was used to generate graphs and to perform statistical analysis. $P$ values were obtained using either the two-tailed Student's t-test, MannWhitney $U$ test or the Kruskal-Wallis test. Differences were considered statistically significant when $p<0.05\left({ }^{*} p<0.01,{ }^{* *} p<0.001,{ }^{* * *} p<0.0001\right)$. Absence of statistical annotation indicates non-significance.

\section{DATA AND SOFTWARE AVAILABILITY}

ChIP-seq raw data is available in the Sequence Read Archive (SRA) repository accession code PRJNA674763. RNA-seq data was deposited in the Gene Expression Omnibus database under accession number GSE160503. 


\section{References}

1. Kennedy, B.K. et al. Geroscience: linking aging to chronic disease. Cell 159, 709-713 (2014).

2. Gorgoulis, V. et al. Cellular Senescence: Defining a Path Forward. Cell 179, 813-827 (2019).

3. Narita, M. et al. Rb-mediated heterochromatin formation and silencing of E2F target genes during cellular senescence. Cell 113, 703-716 (2003).

4. Zhang, W. et al. Aging stem cells. A Werner syndrome stem cell model unveils heterochromatin alterations as a driver of human aging. Science 348, 1160-1163 (2015).

5. Swanson, E.C., Manning, B., Zhang, H. \& Lawrence, J.B. Higher-order unfolding of satellite heterochromatin is a consistent and early event in cell senescence. J Cell Biol 203, 929-942 (2013).

6. De Cecco, M. et al. Genomes of replicatively senescent cells undergo global epigenetic changes leading to gene silencing and activation of transposable elements. Aging Cell 12, 247-256 (2013).

7. Nishibuchi, G. \& Dejardin, J. The molecular basis of the organization of repetitive DNA-containing constitutive heterochromatin in mammals. Chromosome Res 25, 77 87 (2017).

8. Freund, A., Laberge, R.M., Demaria, M. \& Campisi, J. Lamin B1 loss is a senescenceassociated biomarker. Mol Biol Cell 23, 2066-2075 (2012).

9. De Cecco, M. et al. L1 drives IFN in senescent cells and promotes age-associated inflammation. Nature 566, 73-78 (2019).

10. Simon, M. et al. LINE1 Derepression in Aged Wild-Type and SIRT6-Deficient Mice Drives Inflammation. Cell Metab 29, 871-885 e875 (2019).

11. Hu, H. et al. ZKSCAN3 counteracts cellular senescence by stabilizing heterochromatin. Nucleic Acids Res 48, 6001-6018 (2020).

12. Deng, L. et al. Stabilizing heterochromatin by DGCR 8 alleviates senescence and osteoarthritis. Nat Commun 10, 3329 (2019).

13. d'Adda di Fagagna, F. et al. A DNA damage checkpoint response in telomere-initiated senescence. Nature 426, 194-198 (2003).

14. Beliveau, A. et al. p53-dependent integration of telomere and growth factor deprivation signals. Proc Natl Acad Sci U S A 104, 4431-4436 (2007).

15. Valgardsdottir, R. et al. Transcription of Satellite III non-coding RNAs is a general stress response in human cells. Nucleic Acids Res 36, 423-434 (2008).

16. Pal, S., Postnikoff, S.D., Chavez, M. \& Tyler, J.K. Impaired cohesion and homologous recombination during replicative aging in budding yeast. Sci $A d v$ 4, eaaq0236 (2018).

17. Fumagalli, M. et al. Telomeric DNA damage is irreparable and causes persistent DNAdamage-response activation. Nat Cell Biol 14, 355-365 (2012).

18. Hewitt, G. et al. Telomeres are favoured targets of a persistent DNA damage response in ageing and stress-induced senescence. Nat Commun 3, 708 (2012).

19. Williams, E.S. \& Bailey, S.M. Chromosome orientation fluorescence in situ hybridization (CO-FISH). Cold Spring Harb Protoc 2009, pdb prot5269 (2009).

20. Grolimund, L. et al. A quantitative telomeric chromatin isolation protocol identifies different telomeric states. Nat Commun 4, 2848 (2013).

21. Fujita, K. et al. Positive feedback between p53 and TRF2 during telomere-damage signalling and cellular senescence. Nat Cell Biol 12, 1205-1212 (2010).

22. Mendez-Bermudez, A. et al. Genome-wide Control of Heterochromatin Replication by the Telomere Capping Protein TRF2. Mol Cell 70, 449-461 e445 (2018). 
23. Karlseder, J., Smogorzewska, A. \& de Lange, T. Senescence induced by altered telomere state, not telomere loss. Science 295, 2446-2449 (2002).

24. Goodarzi, A.A. et al. ATM signaling facilitates repair of DNA double-strand breaks associated with heterochromatin. Mol Cell 31, 167-177 (2008).

25. Gentili, M. et al. The N-Terminal Domain of cGAS Determines Preferential Association with Centromeric DNA and Innate Immune Activation in the Nucleus. Cell Rep 26, 2377-2393 e2313 (2019).

26. Campisi, J. \& d'Adda di Fagagna, F. Cellular senescence: when bad things happen to good cells. Nat Rev Mol Cell Biol 8, 729-740 (2007).

27. Bignell, G.R. et al. Signatures of mutation and selection in the cancer genome. Nature 463, 893-898 (2010).

28. Beroukhim, R. et al. The landscape of somatic copy-number alteration across human cancers. Nature 463, 899-905 (2010).

29. Sawyer, J.R. et al. Jumping translocations of 1q12 in multiple myeloma: a novel mechanism for deletion of $17 \mathrm{p}$ in cytogenetically defined high-risk disease. Blood 123, 2504-2512 (2014).

30. Gagos, S. et al. Pericentromeric instability and spontaneous emergence of human neoacrocentric and minute chromosomes in the alternative pathway of telomere lengthening. Cancer Res 68, 8146-8155 (2008).

31. Lototska, L. et al. Human RAP1 specifically protects telomeres of senescent cells from DNA damage. EMBO Rep 21, e49076 (2020).

32. Bradshaw, P.S., Stavropoulos, D.J. \& Meyn, M.S. Human telomeric protein TRF2 associates with genomic double-strand breaks as an early response to DNA damage. Nat Genet 37, 193-197 (2005).

33. Mao, Z., Seluanov, A., Jiang, Y. \& Gorbunova, V. TRF2 is required for repair of nontelomeric DNA double-strand breaks by homologous recombination. Proc Natl Acad Sci U S A 104, 13068-13073 (2007).

34. Rendon-Gandarilla, F.J. et al. Telomeric Repeat-Binding Factor Homologs in Entamoeba histolytica: New Clues for Telomeric Research. Front Cell Infect Microbiol 8, 341 (2018).

35. Rai, T.S. \& Adams, P.D. ChIP-Sequencing to Map the Epigenome of Senescent Cells Using Benzonase Endonuclease. Methods Enzymol 574, 355-364 (2016).

36. Chen, S., Zhou, Y., Chen, Y. \& Gu, J. fastp: an ultra-fast all-in-one FASTQ preprocessor. Bioinformatics 34, i884-i890 (2018).

37. Langmead, B. \& Salzberg, S.L. Fast gapped-read alignment with Bowtie 2. Nat Methods 9, 357-359 (2012).

38. Stovner, E.B. \& Saetrom, P. epic2 efficiently finds diffuse domains in ChIP-seq data. Bioinformatics 35, 4392-4393 (2019).

39. Amemiya, H.M., Kundaje, A. \& Boyle, A.P. The ENCODE Blacklist: Identification of Problematic Regions of the Genome. Sci Rep 9, 9354 (2019).

40. Bolger, A.M., Lohse, M. \& Usadel, B. Trimmomatic: a flexible trimmer for Illumina sequence data. Bioinformatics 30, 2114-2120 (2014).

41. Dobin, A. et al. STAR: ultrafast universal RNA-seq aligner. Bioinformatics 29, 15-21 (2013).

42. Love, M.I., Huber, W. \& Anders, S. Moderated estimation of fold change and dispersion for RNA-seq data with DESeq2. Genome Biol 15, 550 (2014). 

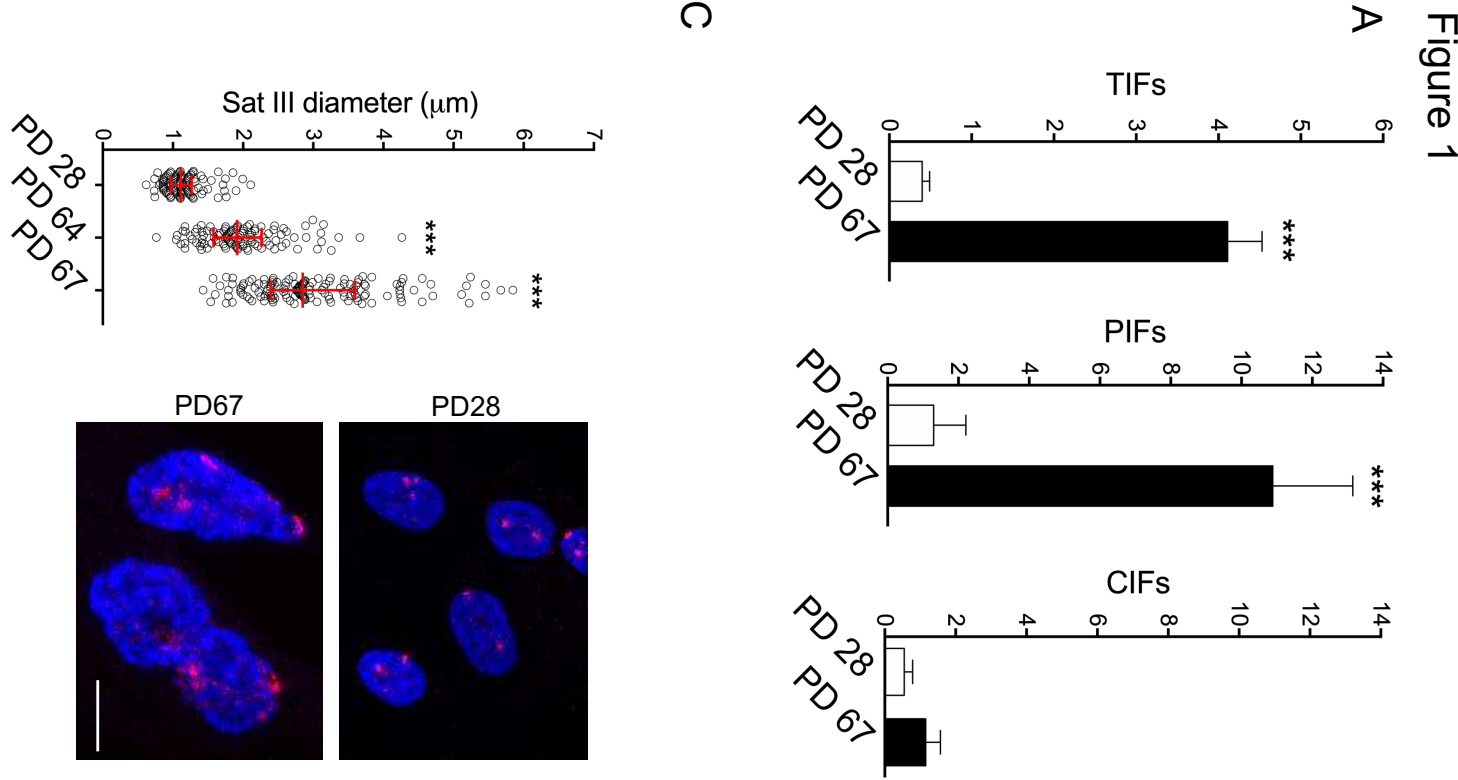

$\varpi$
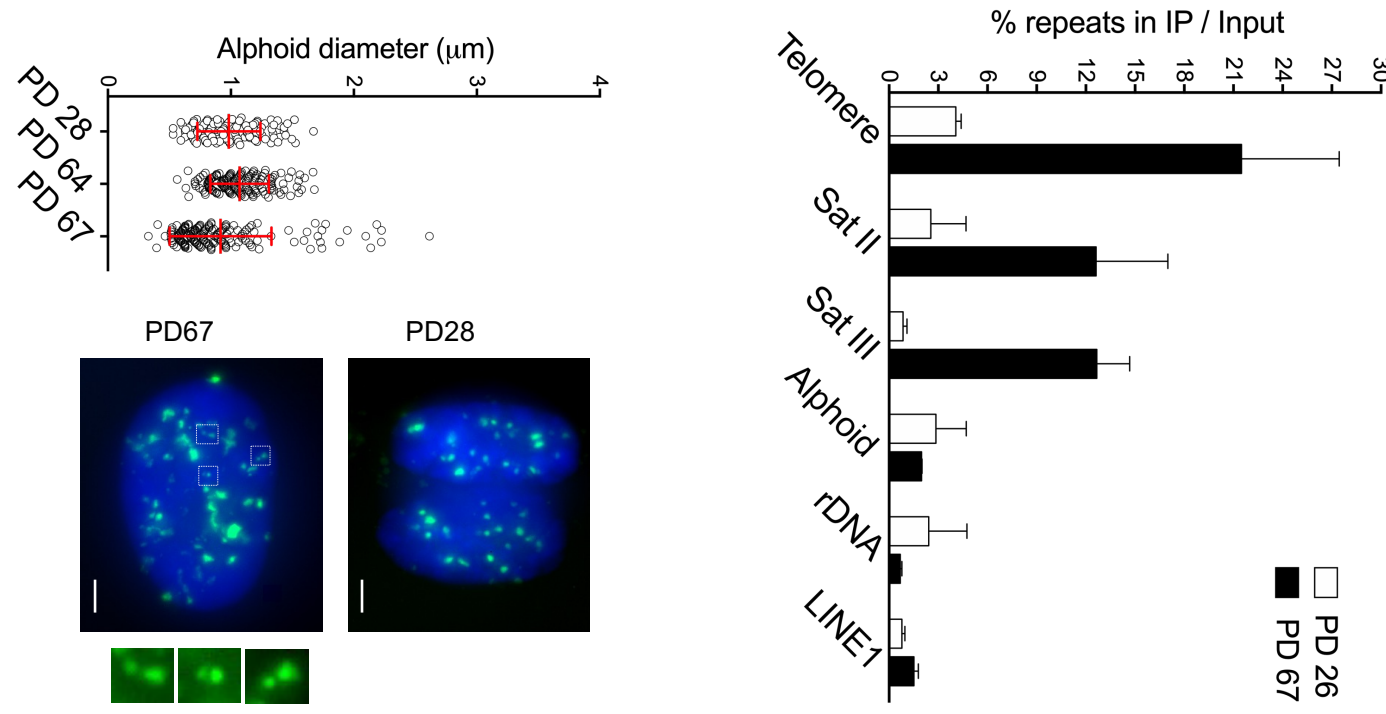
Figure 1. Pericentromeric damage during replicative senescence

(A) DNA damage quantification by immunofluorescence colocalization of 53BP1 protein together with a telomeric (TIFs), Satellite III (PIFs) or centromeric (CIFs) PNA probe in young (PD 28) and senescent (PD 67) MRC-5 cells. TIFs represent the number of colocalizations per nucleus, while PIFs and CIFs shows the percentage of the PNA signal colocalizing with 53BP1. Data show the mean \pm SD of three biological replicates. Statistical analyses were performed using the Mann-Whitney U-test ( $\left.{ }^{* * *} P<0.0001\right)$. (B) Quantification of $\mathrm{YH} 2 \mathrm{AX}$ ChIP-seq reads composed of pure repeated sequences in MRC-5 cells. The number of repetitive sequence reads obtained in the immunoprecipitated samples was normalized to the total number of reads in the input. The diameter of Satellite III (Sat III) (C) and alphoid (D) PNA spots in young (PD 28) and senescent (PD 67) cells was quantified. Scale bar $=10 \mu \mathrm{m}$. Error bars show the mean $\pm \mathrm{SD}$ of three independent experiments. Statistical analyses were performed using the Kruskal-Wallis test $\left({ }^{* * *} P<0.0001\right)$. 
Figure 2

A

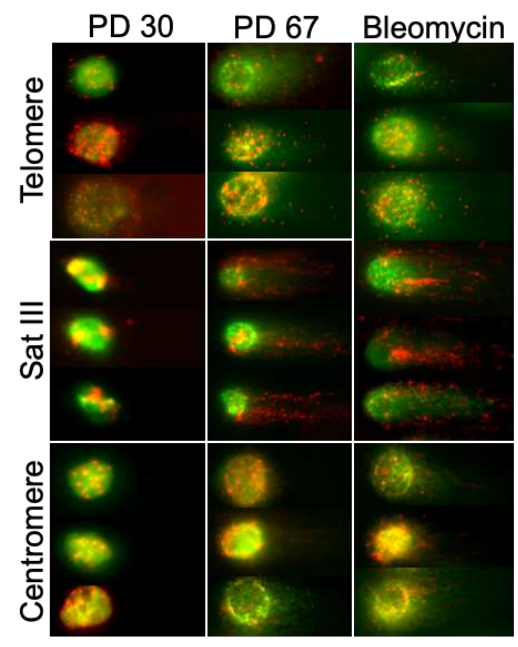

C

Sat II Sat III Alu

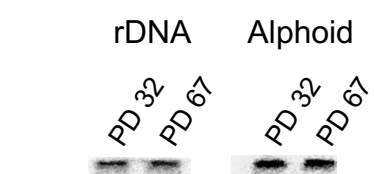

के $\hat{0} \hat{3}^{2} \hat{0} \hat{3}^{2} \hat{0}$

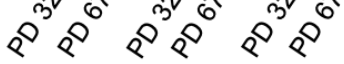

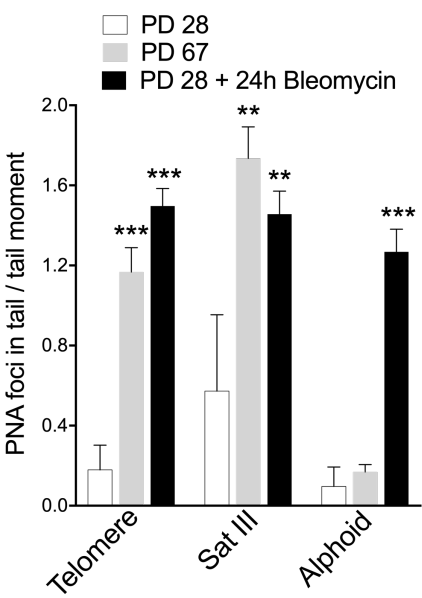

B

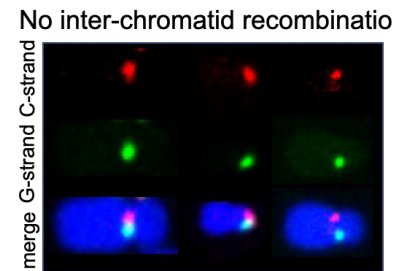

Inter-chromatid recombination
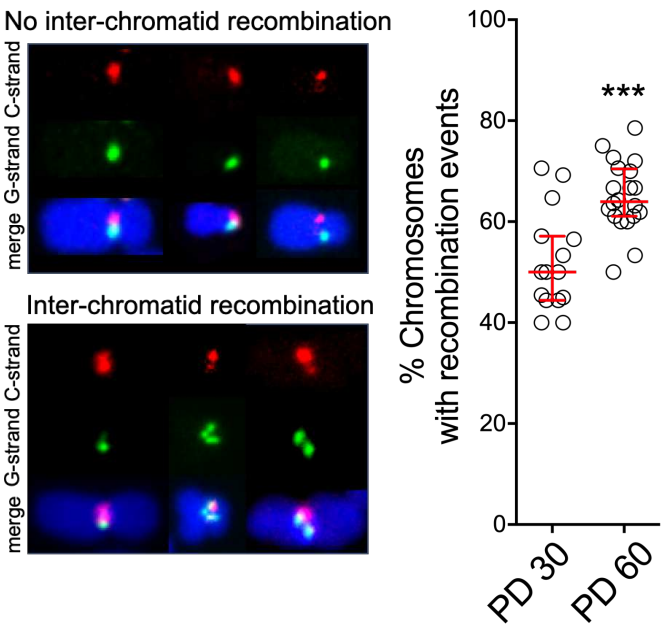

$350 \mathrm{~kb}-$

$280 \mathrm{~kb}-$

$200 \mathrm{~kb}-$

$100 \mathrm{~kb}-$

$48 \mathrm{~kb}-$

$20 \mathrm{~kb}-$

$15 \mathrm{~kb}-$

$10 \mathrm{~kb}-$

$6 \mathrm{~kb}-$

$3 \mathrm{~kb}-$

$2 \mathrm{~kb}-$

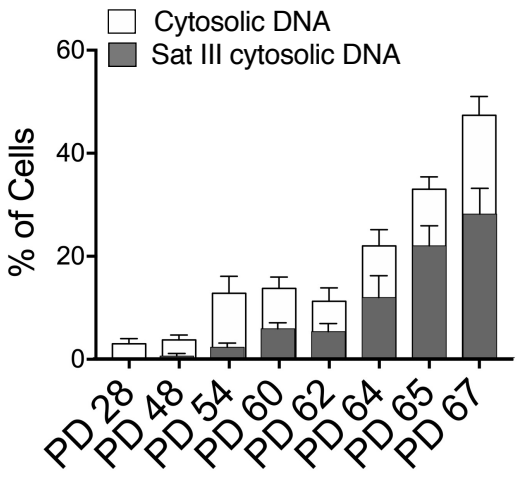

$50 \mathrm{~kb}-$ 
Figure 2. Selective pericentromeric DNA instability at senescence onset

(A) Neutral comet assay. Bleomycin treatment $(50 \mu \mathrm{g} / \mathrm{ml}$ for $24 \mathrm{~h})$ of young MRC- 5 cells was used as a positive control for double-strand breaks. Graphs show the number of PNA foci in the tail of the comet divided by the tail moment (tail length $\times$ DNA signal in the tail / total DNA signal). DNA is shown in green (YOYO-1), whereas PNA probe signal is in red. Error bars represent SEMs of at least 60 cells. Statistical analyses were performed using the Kruskal-Wallis test $\left({ }^{* *} P<0.001 ;{ }^{* * *} P<0.0001\right)$. (B) Pericentromeric instability assessed by COFISH in young (PD 28) and pre-senescent (PD 60) MRC-5 cultures. Error bars \pm SD of at least 15 metaphases. Mann-Whitney U-test $\left({ }^{* * *} P<0.0001\right)$ was used for statistical analysis. (C) Southern blots showing the distribution of MRC-5 Sat II, Sat III and Alu repeats at different PDs following digestion with HindIII. DNA was digested with BamHI to assess for rDNA and alphoid repeat size distribution. Separation of DNA fragments was carried out using a pulsed field gel electrophoresis system. (D) Percentage of cells with cytosolic DNA stained with a Sat III PNA probe. Error bars show the SD of three biological replicates. 
Figure 3

A

B
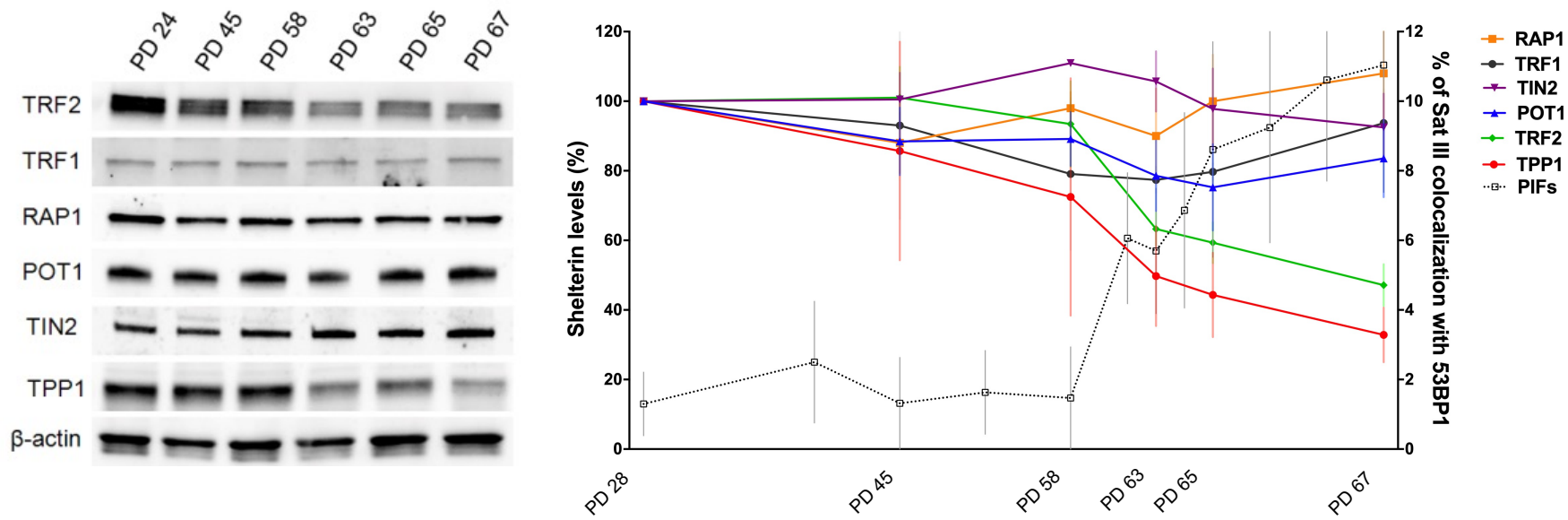

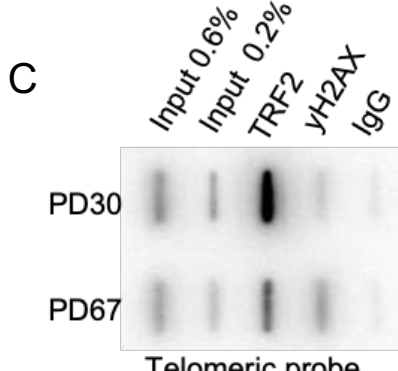

Telomeric probe

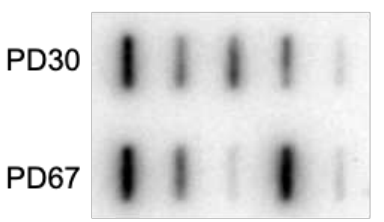

Sat III probe
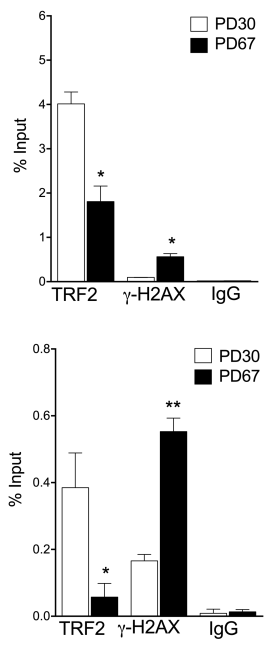

D

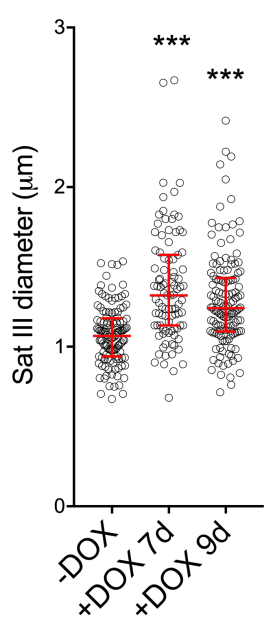

E

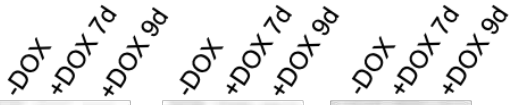

$350 \mathrm{~kb}$

$280 \mathrm{~kb}$ -

$200 \mathrm{~kb}$ -

$100 \mathrm{~kb}$ -

$50 \mathrm{~kb}$ -

Sat II
Sat III
F

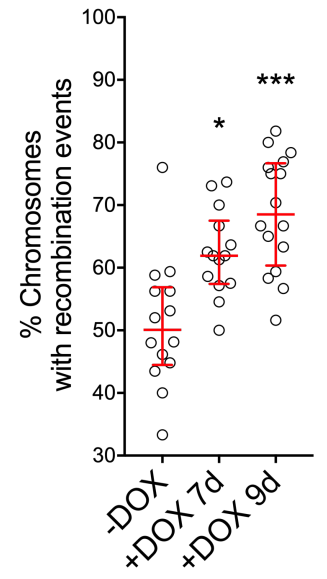

G

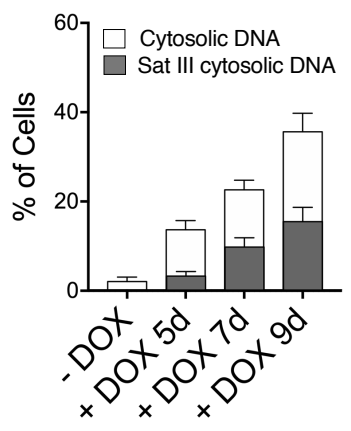

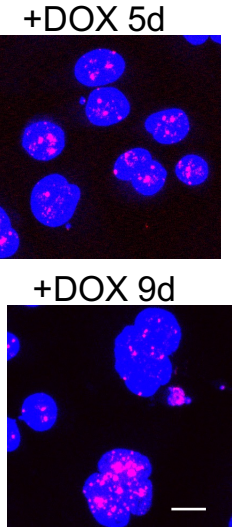

Sat III + DAPI 
Figure 3. TRF2 protects against $\mathrm{PCH}$ damage

(A) Western blotting of shelterin proteins at different population doublings in MRC-5 cells and quantification (B) of two biological replicates. (C) Native ChIP of MRC-5 cells at the indicated population doublings. The immunoprecipitated DNA obtained with TRF2 and $\mathrm{YH} 2 \mathrm{AX}$ antibodies, and IgG control was spotted onto slot blots and hybridized with either a telomeric or a Sat III radioactively labelled probe. Quantification shows the enrichment as a percentage of input from three independent experiments. Statistical analysis was performed using unpaired two-tailed $t$ test. Error bars represent mean $\pm S D$; ${ }^{*} p<0.01,{ }^{* *} p<0.001$. (D) Sat III opening, (E) Sat II, Sat III and Alu length distribution, (F) Sat III interchromatid recombination events and $(G)$ cytosolic Sat III DNA in HeLa cells treated with doxycycline (DOX) to deplete TRF2 expression for 7 or 9 days at a final concentration of $1 \mu \mathrm{g} / \mathrm{ml}$. Data represent mean \pm SD of three biological replicates. Statistical analyses were performed using the Kruskal-Wallis test $\left({ }^{*} P\right.$ $\left.<0.01 ;{ }^{* * *} P<0.0001\right)$. 
Figure 4

A
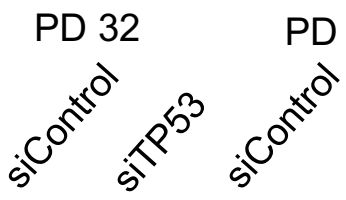

TRF2

p53

Actin

TRF2 100\%

$96 \% \quad 60 \%$

p53 100\%

$5 \% \quad 100 \%$

$5 \% \quad 100 \% \quad 3 \%$

C

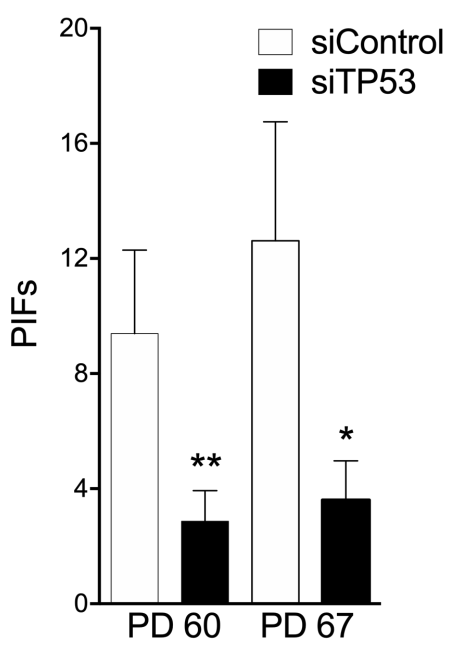

D
B
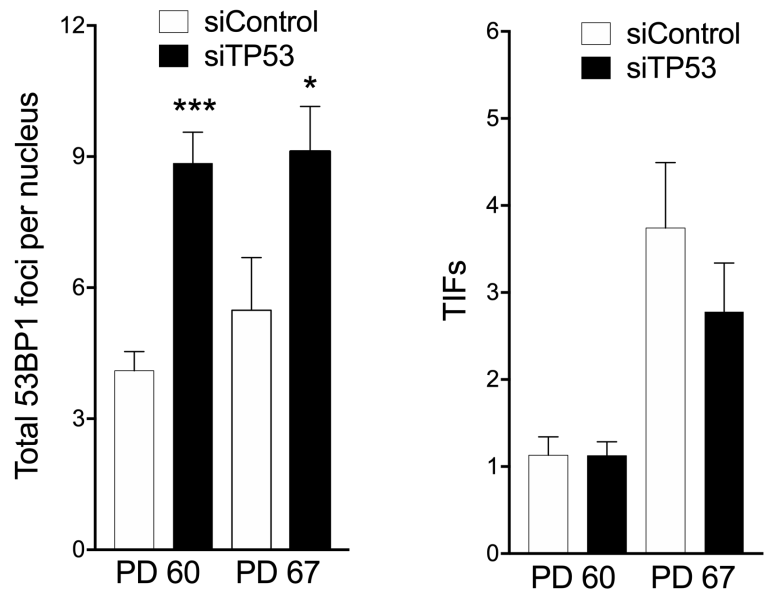
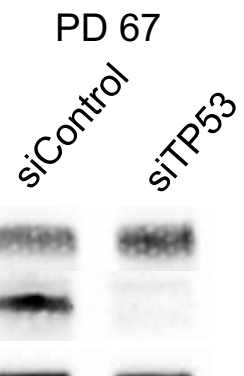

$45 \% \quad 75 \%$

$\%$

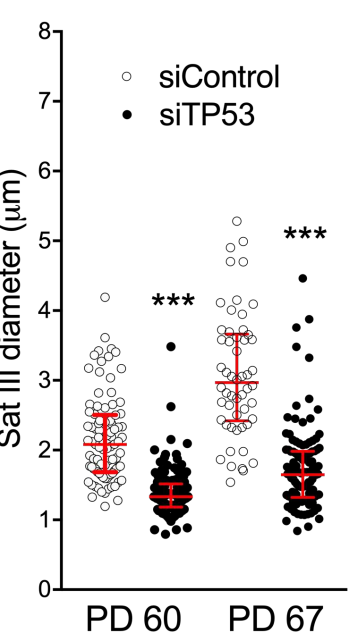

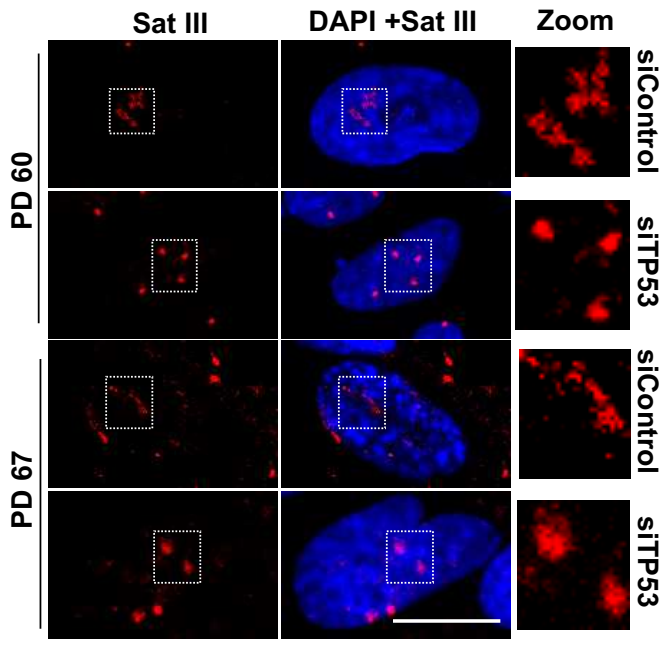


Figure 4. TP53-dependent TRF2 downregulation

(A) Immunoblotting showing the expression of TRF2 and p53 in MRC-5 incubated for 3 days with the corresponding siRNA. (B) Immunofluorescence detection of total 53BP1 spots per nucleus, mean number of TIFs, (C) PIFs and (D) Sat III opening. Data represent mean \pm SD of three biological replicates. Statistical analyses were performed using the Kruskal-Wallis test $\left({ }^{*} P<0.01 ;{ }^{* *} P\right.$ $\left.<0.001 ;{ }^{* * *} P<0.0001\right)$. 
Figure 5

A
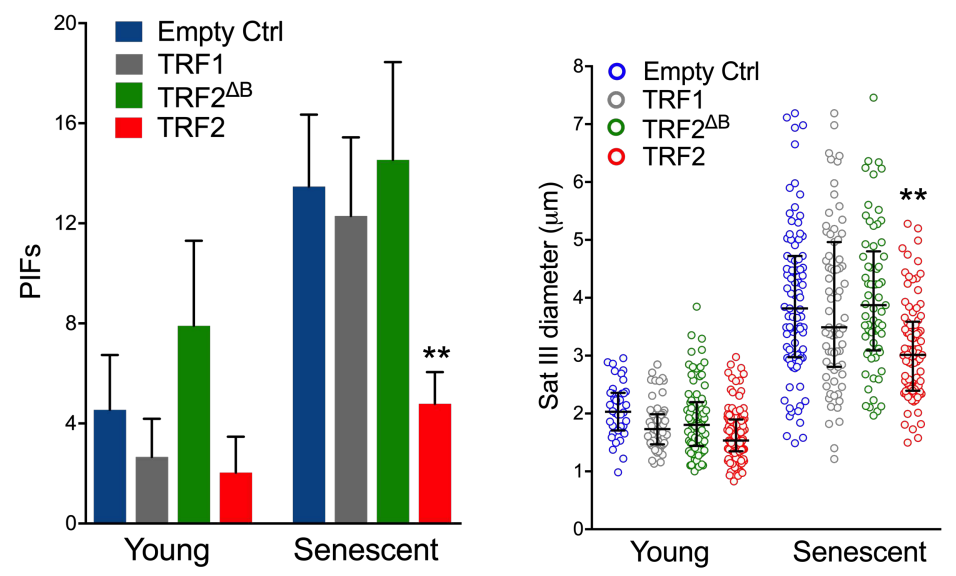

$350 \mathrm{~kb}$ -

$280 \mathrm{~kb}$ -

$200 \mathrm{~kb}$ -

$100 \mathrm{~kb}$ -

50 kb -

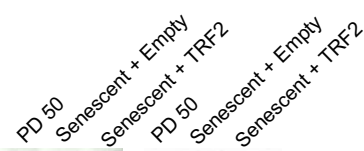

C
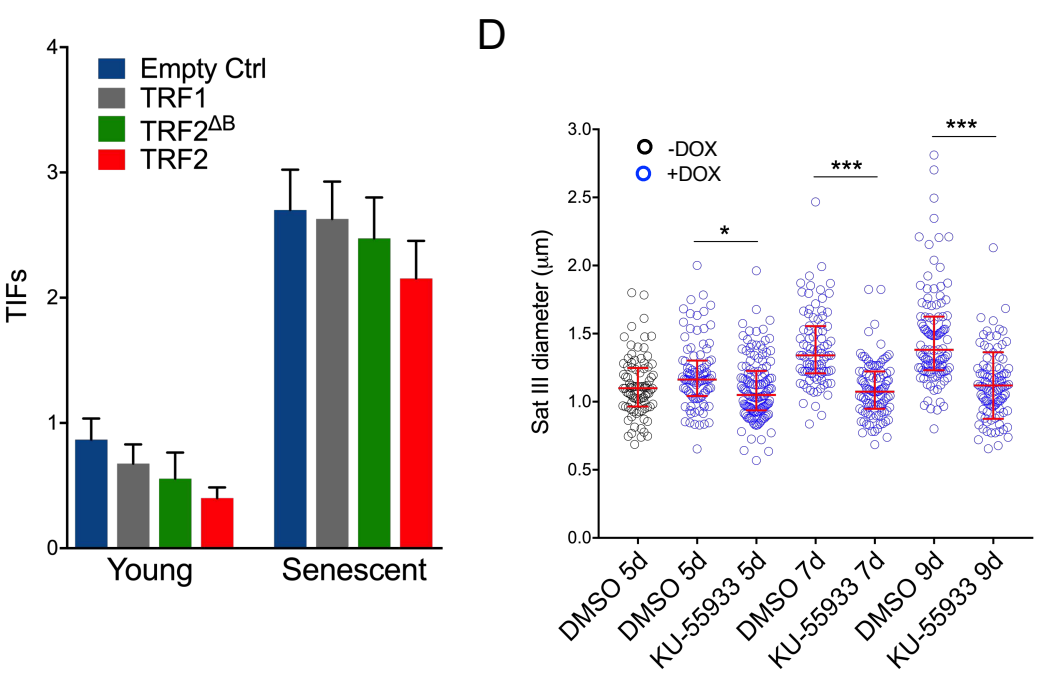

E
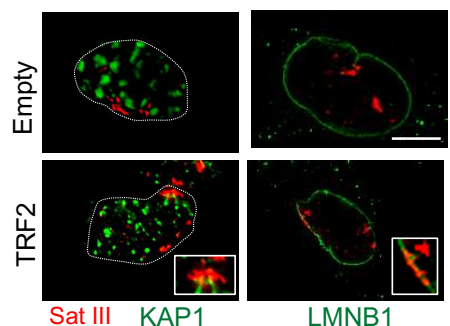

Sat III

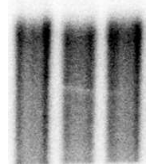

Alu
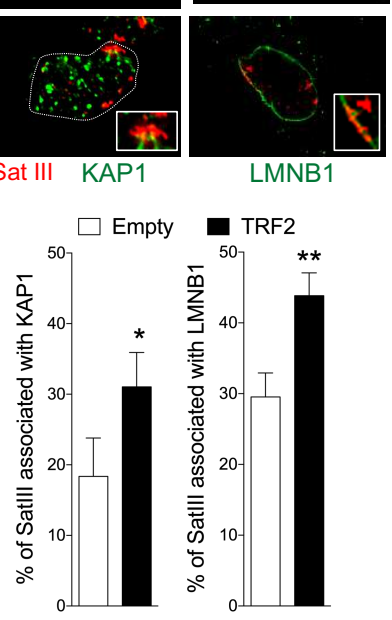

F

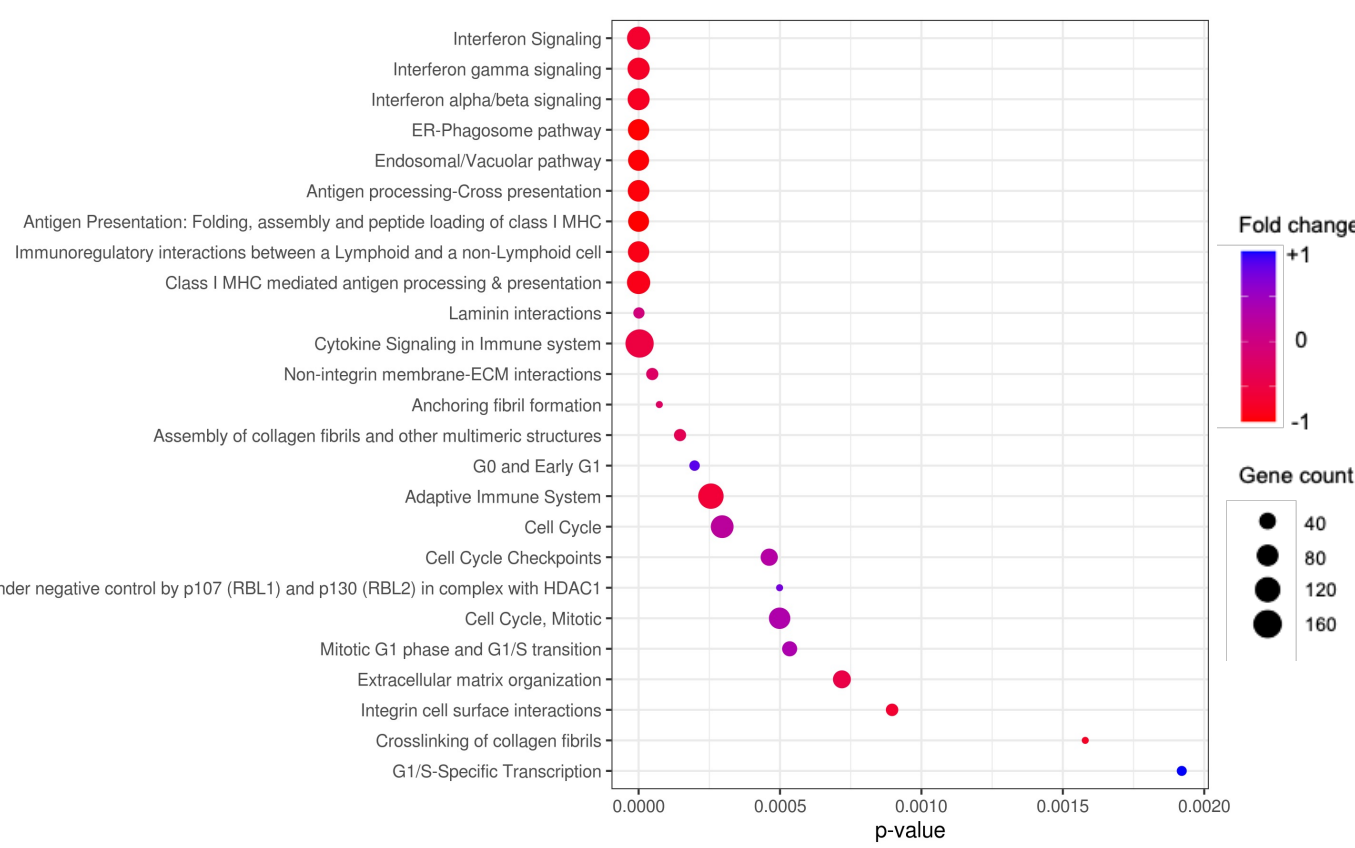


Figure 5. TRF2 is necessary to maintain PCH stability during replicative senescence

(A) PIFs and Sat III opening of young MRC-5 cells (PD 28) transduced for 6 days with at a lentivirus containing an empty vector or the full-length TRF2. Presenescent cells (PD 50) were transduced with empty or TRF2 expressing lentivirus and grow until they senescence (PD 71 for empty control and PD 75 for TRF2 expressing cells) at $5 \%$ oxygen. Data represent mean \pm SD of three biological replicates. Statistical analyses were performed using the KruskalWallis test $\left({ }^{*} P<0.01 ;{ }^{* *} P<0.001 ;{ }^{* *} P<0.0001\right)$. (B) Sat III and Alu length distribution. The membrane was initially hybridized with a Sat III probe, followed by an Alu probe. (C) TIFs for the conditions described in A. (D) Sat III opening in HeLa cells expressing a doxycycline inducible shTRF2 vector and treated with $10 \mu \mathrm{M}$ of the ATM inhibitor KU-55933 for $24 \mathrm{~h}$. Data represent mean \pm SD of three biological replicates. Statistical analyses were performed using the Kruskal-Wallis test $\left({ }^{*} P<0.01 ;{ }^{* *} P<0.0001\right)$. (E) Sat III PNA probe co-staining with Kap1 or Lamin B1 in MRC-5 senescent cells expressing TRF2 or an empty vector control. (F) Reactome pathway analysis of RNA-seq differential expression data of senescent cells with and without ectopic expression of TRF2. 
Figure 6

A
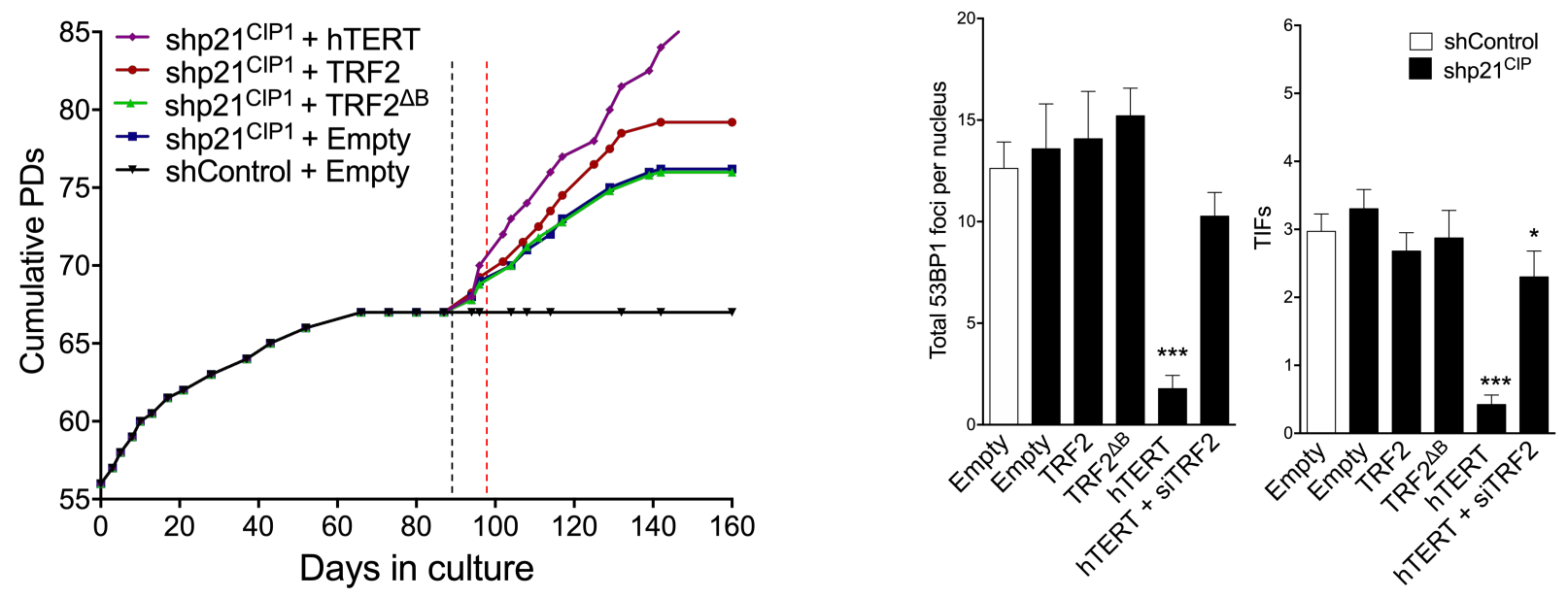

C
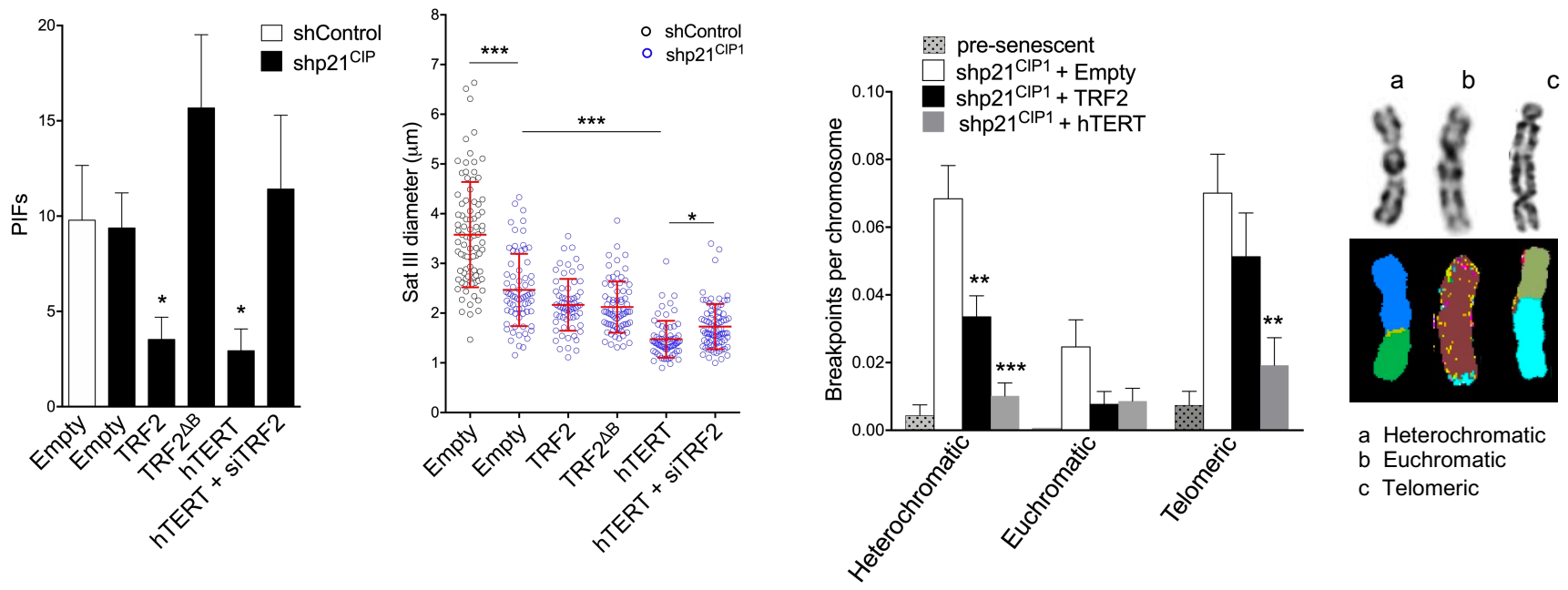

a Heterochromatic b Euchromatic c Telomeric 
Figure 6. TRF2 is required for pericentromeric DNA stability in postsenescent cells

(A) Growth curve of senescence cells transduced with sh21 $1^{\mathrm{CIP} 1}$ together with either empty, TRF2, TRF2 ${ }^{\triangle B}$ or hTERT lentiviral vectors (black dotted line). Cells were collected 10 days post infection (red dotted line). (B) Total damage, TIFs, (C) PIFs and Sat III opening of the conditions described in A. TRF2 downregulation in hTERT expressing cells was carried out for three days using siRNAs. Data represent mean \pm SD of three biological replicates. Statistical analyses were performed using the Kruskal-Wallis test $\left({ }^{*} P<0.01\right.$; ${ }^{* * *} P<$ 0.0001). (D) Chromosome breakpoints quantification identified by Inverted-DAPI Banding and multicolor FISH. Examples show an heterochromatic $[\operatorname{der}(\mathrm{X}) \mathrm{t}(\mathrm{X} ; 9)(\mathrm{q} 22.1 ; \mathrm{q} 11)]$, an euchromatic $[\operatorname{der}(7) \mathrm{t}(2 ; 7)]$ and a telomeric [dic(1;17)(pter;pter)] chromosome breakpoint. Error bars represent the mean \pm SD of approximately 15 metaphases. Statistical analyses were performed using the Kruskal-Wallis test $\left({ }^{* *} P<0.001 ;{ }^{* * *} P<0.0001\right)$. 


\section{Supplementary Files}

This is a list of supplementary files associated with this preprint. Click to download.

- SupFigures.pdf 